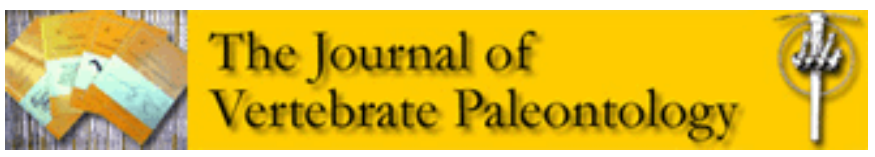

\title{
Phylogenetic placement of Adalatherium hui (Mammalia, Gondwanatheria) from the Late Cretaceous of Madagascar: implications for allotherian relationships
}

\begin{tabular}{|r|l|}
\hline Journal: & Journal of Vertebrate Paleontology \\
\hline Manuscript ID & JVP-2020-0020.R1 \\
\hline Danuscript Type: & Memoir Submission (consult Memoirs Editor well in advance) \\
\hline Author: & n/a \\
\hline Key Wote List of Authors: & $\begin{array}{l}\text { Hoffmann, Simone; New York Institute of Technology College of } \\
\text { Osteopathic Medicine, Anatomy } \\
\text { Beck, Robin; University of Salford, 2School of Science, Engineering and } \\
\text { Environment } \\
\text { Wible, John; Carnegie Museum of Natural History, Section of Mammals } \\
\text { Rougier, Guillermo; University of Louisville, Anatomical Sciences and } \\
\text { Neurobiology } \\
\text { Krause, David; Denver Museum of Nature and Science, Earth Sciences }\end{array}$ \\
\hline & \begin{tabular}{l} 
Gondwanatheria, Phylogeny, Madagascar \\
\hline
\end{tabular}
\end{tabular}

\section{SCHOLARONE ${ }^{m}$ Manuscripts}


Phylogenetic placement of Adalatherium hui (Mammalia, Gondwanatheria) from the Late Cretaceous of Madagascar: implications for allotherian relationships

\section{SIMONE HOFFMANN, ${ }^{1, *}$ ROBIN M. D. BECK, ${ }^{2}$ JOHN R. WIBLE, ${ }^{3}$ GUILLERMO W. ROUGIER, ${ }^{4}$ DAVID W. KRAUSE 5,6}

${ }^{1}$ Department of Anatomy, New York Institute of Technology, College of Osteopathic Medicine, Old Westbury, NY 11568, U.S.A., shoffm04@nyit.edu;

${ }^{2}$ School of Science, Engineering and Environment, University of Salford, Manchester M5 4WT, U.K., R.M.D.Beck@salford.ac.uk;

${ }^{3}$ Section of Mammals, Carnegie Museum of Natural History, 5800 Baum Boulevard, Pittsburgh, Pennsylvania 15206, U.S.A., wiblej@carnegiemnh.org;

${ }^{4}$ Department of Anatomical Sciences and Neurobiology, University of Louisville, Louisville, Kentucky 40202, U.S.A., grougier@louisville.edu;

${ }^{5}$ Department of Earth Sciences, Denver Museum of Nature \& Science, Denver, Colorado 80205, U.S.A., David.Krause@dmns.org;

${ }^{6}$ Department of Anatomical Sciences, Stony Brook University, Stony Brook, New York 117948081, U.S.A.

* Corresponding author

RH: HOFFMANN ET AL.—PHYLOGENY OF ADALATHERIUM HUI 


\begin{abstract}
The phylogenetic position of Gondwanatheria within Mammaliaformes has
historically been controversial. The well-preserved skeleton of Adalatherium hui from the Late

Cretaceous of Madagascar offers a unique opportunity to address this issue, based on

morphological data from the whole skeleton. Gondwanatheria were, until recently, known only

from fragmentary dental and mandibular material, as well as a single cranium. The holotype of
\end{abstract}

A. hui provides the first postcranial skeleton for gondwanatherians and substantially increases the amount of character data available to score. We sampled 530 characters and 84 cynodonts (including 34 taxa historically affiliated with Allotheria) to test the phylogenetic relationships of Gondwanatheria and Allotheria using parsimony, undated Bayesian, and tip-dated Bayesian methods. We tested three lower dental formulae for Adalatherium, because its postcanines are distinctly different from those of other mammaliaforms and cannot readily be homologized with any known dental pattern. In all analyses, Adalatherium is recovered within Gondwanatheria, most frequently outside of Sudamericidae or Ferugliotheriidae, which is congruent with establishment of the family Adalatheriidae. The different dental coding schemes do not greatly impact the position of Adalatherium, although there are differences in character optimization. In all analyses, Gondwanatheria are placed within Allotheria, either as sister to Multituberculata, nested within Multituberculata, as sister to Cifelliodon (and Euharamiyida), or in a polytomy with other allotherians. The composition of Allotheria varies in our analyses. The haramiyidans Haramiyavia and Thomasia are placed outside of Allotheria in the parsimony and tip-dated Bayesian analyses, but in a polytomy with other allotherians in the undated Bayesian analyses. 


\section{INTRODUCTION}

The Late Cretaceous to Paleogene Gondwanatheria are one of the least well known early mammaliaform clades from the southern hemisphere, and currently include ten valid, monotypic genera: Ferugliotherium [=Vucetichia], Trapalcotherium, Gondwanatherium, Sudamerica, Bharattherium [=Dakshina], Lavanify, Vintana, Galulatherium, Greniodon, and Adalatherium. With the exception of the most recently described taxa, Vintana (Krause et al., 2014) and Adalatherium (Krause et al., 2020), gondwanatherians are known only from fragmentary dental and gnathic remains. Based on the very limited morphological information available, the phylogenetic position of Gondwanatheria within Mammaliaformes has historically been controversial, and has included a proposed close relationship to (1) the placental clade Xenarthra (Scillato-Yané and Pascual, 1985; Bonaparte, 1986a, 1986b, 1986c, 1987, 1988, 2017; Bonaparte and Pascual, 1987; Mones, 1987) or (2) members of Allotheria, which have at various times been considered to include Multituberculata, Haramiyida (sensu Butler, 2000), and Euharamiyida (e.g., Krause et al., 1992, 2014, 2020; Bonaparte et al., 1993; Krause, 1993; Krause and Bonaparte, 1993; Kielan-Jaworowska and Bonaparte, 1996; Gurovich, 2006; Pascual and OrtizJaureguizar, 2007; Gurovich and Beck, 2009; Rougier et al., 2009; Rougier, Gaetano et al., 2011; Bi et al., 2014). Pascual et al. (1999) concluded that Gondwanatheria could not be assigned with certainty to any mammalian clade and simply referred to them as Mammalia incertae sedis, an opinion followed in the compendium on Mesozoic mammals by Kielan-Jaworowska et al. (2004). It should be noted that Kielan-Jaworowska et al. (2004) used a stem-based definition of Mammalia that includes Mammaliaformes. It is likely that Pascual et al. (1999) were also referring to Mammaliaformes rather than crown Mammalia when they assigned Gondwanatheria 
to 'Mammalia incertae sedis.' For completeness, it bears mentioning that Vintana, as a representative of Gondwanatheria, has been found to lie outside of Allotheria in some recent analyses (Han et al., 2017; Wang et al., 2019). Finally, relationships between gondwanatherians and the bizarre Cenozoic Groeberia and Patagonia have also been proposed (Chimento et al., 2014) but the analysis and results were criticized by Beck (2017). Zimicz and Goin (2020) provided a more detailed critique of Chimento et al.'s (2014) conclusion to assign Groeberia to Gondwanatheria, but did not discuss Patagonia. We consider the putative gondwanatherian relationships of Groeberia refuted and those of Patagonia unsubstantiated and unlikely; as such, they will not be discussed further in this paper.

The first formal phylogenetic analysis to include Gondwanatheria was conducted by Gurovich and Beck (2009), who placed the gondwanatherians Sudamerica, Gondwanatherium, and Ferugliotherium in a polytomy with 'plagiaulacidan' and cimolodontan multituberculates within Allotheria, with the haramiyidans Thomasia and Haramiyavia placed outside of Mammaliaformes. Based on a greatly expanded sample of multituberculates and gondwanatherians (including the first cranium of a gondwanatherian, that of Vintana), Krause et al. (2014) recovered Allotheria, including Multituberculata, Gondwanatheria, Haramiyavia, Thomasia, and Arboroharamiya, within Mammalia. Although Multituberculata, Gondwanatheria, and Euharamiyida (including Arboroharamiya) were still recovered within Mammalia in a parsimony analysis by Krause et al. (2020), the haramiyidans Haramiyavia and Thomasia were placed outside of Mammaliaformes.

The composition and position of Allotheria have gained attention in recent years because of the implications for the timing of the origin of Mammalia (sensu Rowe, 1988). Contrasting hypotheses have either (1) placed Allotheria, including the Late Triassic-to-Jurassic 
Haramiyavia and Thomasia, within Mammalia (e.g., Yuan et al., 2013; Zheng et al., 2013; Bi et al., 2014; Krause et al., 2014; Han et al., 2017; Wang et al., 2019), implying that Mammalia originated by the Late Triassic, or (2) placed Multituberculata within Mammalia but Haramiyavia and Thomasia outside of Mammalia (e.g., Zhou et al., 2013; Close et al., 2015; Luo et al., 2015, 2017; Huttenlocker et al., 2018), compatible with an origin of mammals some 40 million years later, in the latest Early Jurassic, and potentially a relatively "explosive" diversification (Cifelli and Davis, 2013:161). Supporting a possible close relationship among Gondwanatheria, Multituberculata, and Haramiyida are the presence of postcanines with numerous cusps that are arranged longitudinally in multiple rows, enlarged incisors, and, typically, loss of canines. The discovery of a nearly complete and well-preserved skeleton of the gondwanatherian Adalatherium hui (UA 9030) from the Late Cretaceous of Madagascar (Krause et al., 2020) provides a unique opportunity to explore phylogenetic relationships of purported allotherian taxa based on morphological data from the whole skeleton.

Here, we test the phylogenetic relationships of the most complete gondwanatherian, Adalatherium and, more broadly, the composition and relationships of Allotheria, using the matrix of Krause et al. (2020). In addition to the parsimony analysis presented in Krause et al. (2020), we (1) employ different coding schemes to test for uncertainty in homologizing the lower dentition of Adalatherium, (2) constrain relationships within Multituberculata to match the current consensus view, and (3) analyze the data set using both undated and tip-dated Bayesian methods. Tip-dated Bayesian inference has only recently been applied to paleontological data sets (e.g., Beck and Lee, 2014; Lee et al., 2014; Close et al., 2015; Bapst et al., 2016; Matzke and Wright, 2016; Turner et al., 2017; Lee and Yates, 2018; Sterli et al., 2018; Beck and Taglioretti, 2019; King and Beck, 2019), but including stratigraphic information could be particularly 
informative in the case of Allotheria because the fossil record of potential allotherian taxa extends from the Late Triassic to the Eocene. Theoretically, including fossil dates might more realistically constrain relationships of taxa from very disparate time periods, and may help distinguish synapomorphies from cases of homoplasy (Lee and Yates, 2018). At the very least, the topologies that result from undated and tip-dated Bayesian analyses of the same data set can differ markedly, and so it is appropriate to investigate both of these approaches (Lee and Yates, 2018; Beck and Taglioretti, 2019; King and Beck, 2019).

Detailed information on the discovery, preservation, and geological context of UA 9030, the holotype and only known specimen of Adalatherium hui, can be found in Krause, Groenke, et al. (this volume), and detailed morphological description and comparisons of the cranium, inner ear, lower jaw, dentition, and postcranial skeleton are presented in various other chapters of the same volume (Krause and Hoffmann, this volume).

Institutional Abbreviations-UA, Université d'Antananarivo, Antananarivo, Madagascar.

Anatomical Abbreviations — c, lower canine; $\mathbf{C}$, upper canine; i, lower incisor; I, upper incisor; $\mathbf{m}$, lower molar; $\mathbf{M}$, upper molar; $\mathbf{p}$, lower premolar; $\mathbf{P}$, upper premolar; $\mathbf{p c}$, lower postcanine; PC, upper postcanine.

Methodological Abbreviations-ACCTRAN, accelerated transformation; CI, ensemble consistency index; ESS, effective sample size; IGR, independent gamma rates; MCC, maximum clade credibility tree; MCMC, Markov Chain Monte Carlo; Mk, Markov k; MPT, most parsimonious tree; PAUP, Phylogenetic Analysis Using PAUP*; PP, Bayesian posterior probability; RAS, random addition sequence; RI, ensemble retention index; TNT, Tree Analysis using New Technology; TBR, tree bisection and reconnection branch swapping. 


\section{MATERIALS AND METHODS}

\section{Morphological Characters}

The matrix of 84 taxa and 530 characters used here to test the phylogenetic relationships of Adalatherium is a modified version of the data set developed by Hoffmann (2016) and subsequently revised by Krause et al. (2020). Characters for this matrix have been culled from various references including Rougier et al. (1997, 1998, 2007), Hopson and Kitching (2001), Luo et al. (2002, 2007, 2011, 2015, 2017), Hu (2006), Wible et al. (2009), Liu and Olson (2010), Rougier, Apesteguía, et al. (2011), O’Leary et al. (2013), Yuan et al. (2013), Zheng et al. (2013), Zhou et al. (2013), Bi et al. (2014, 2018), Krause et al. (2014), Han et al., (2017), and Huttenlocker et al. (2018). Characters specifically intended to resolve relationships among multituberculates were obtained from Simmons (1993), Rougier et al. (1997), KielanJaworowska and Hurum (1997, 2001), Gurovich and Beck (2009), Yuan et al. (2013), and Krause et al. (2014). The character matrix was initially compiled in Mesquite 3.6 (Maddison and Maddison, 2019) and later transferred to MorphoBank to allow simultaneous scoring by authors. The data matrix is available as a NEXUS file in the Supplementary Data section (Supplementary Data 1) or on MorphoBank under Project 3637. In addition, a character list containing further notes and explanations is included in the Supplementary Data section. This list includes references to corresponding character numbers of Krause et al. (2014; indicated as K\#\#\#), Huttenlocker et al. (2018; H\#\#\#), and Han et al. (2017; HAN\#\#\#). A total of 22 characters were newly developed for the matrix implemented by Krause et al. (2020; chars. 16, 27, 43, 44, 47, $48,50,61,64,71,72,73,131,140,146,219,221,222,223,224,291,424)$ and are indicated as 
(NEW) in the character list. Changes to characters are indicated by “ $\sim$ ”. These changes include minor adjustments in wording, and/or a different ordering of character states. Explanations for substantial changes are presented in red font in the character list.

\section{Taxa and Sources}

A total of 84 extinct and extant cynodonts are included in the character-taxon matrix. This matrix focuses particularly on those taxa that are represented by well-preserved specimens, namely those that are known from more than dental or gnathic remains. Taxa that have been affiliated with Allotheria in previous studies and that are most germane to this analysis of gondwanatherian relationships are represented in the matrix regardless of their completeness. These include, in particular, the gondwanatherians Ferugliotherium, Trapalcotherium, Gondwanatherium, Sudamerica, Bharattherium, Lavanify, Galulatherium, and Greniodon, and the haramiyidans Haramiyavia and Thomasia, all of which are represented by rather fragmentary material (isolated teeth and/or partial dentaries). Most of the scorings are based on first-hand observation of original specimens, casts, 3D prints, or Computed Tomography data. A full list of taxa and specimens is provided in the Supplementary Data. Those taxa that one or more of the authors have personally observed are listed with specimen numbers. Literature references were used to supplement direct observations and to score taxa that we were not able to study in person.

Genus-level terminal units were used for most taxa, with two exceptions. The multituberculates Bolodon and Plagiaulax were grouped into a single terminal taxon, Plagiaulacidae, in an effort to maximize available complementary dental and mandibular morphology for scoring this group. The multiple species within Bolodon are known from upper and lower dentitions, whereas Plagiaulax is known solely from dentaries and lower dentitions 
(Simpson, 1928; Kielan-Jaworowska et al., 2004). Secondly, relationships within a number of Late Jurassic multituberculates from the Guimarota coal mine in Portugal are uncertain and many taxa were intentionally over-split to distinguish between upper and lower dentitions (Hahn and Hahn, 2006). We therefore combined scorings for the best-represented genera Kuehneodon, Paulchoffatia, Meketichoffatia, and Pseudobolodon — into one terminal taxon, Guimarota Paulchoffatiidae, in this study.

Here we use the following phylogenetic definitions to describe relevant higher-level clades. We follow Rowe's $(1987,1988)$ definition of Mammaliaformes as the last common ancestor of Morganucodontidae and Mammalia and all of its descendants, and restrict the term Mammalia to the descendants of the last common ancestor of monotremes and therians. We follow Sereno's (2006) definition of Allotheria as the most inclusive clade including Taeniolabis taoensis but not Mus musculus or Ornithorhynchus anatinus; and Simmons's (1993) definition of Multituberculata as the last common ancestor of Paulchoffatia and Cimolodonta. A phylogenetic definition of Gondwanatheria is currently lacking. For the purpose of discussing Gondwanatheria in this paper and as a working hypothesis, we refer to Gondwanatheria as the most inclusive clade including Gondwanatherium but not Taeniolabis, Cifelliodon, or Shenshou. A more explicit definition is at this point difficult to establish because of the uncertain placement of taxa potentially associated with Gondwanatheria in our analyses. As a working hypothesis, we refer to Sudamericidae as the last common ancestor of Vintana and Sudamerica and all of its descendants. We do, however, caution that resolution within Gondwanatheria and at the base of Sudamericidae is poor and that the topology varies among our analyses. More complete fossil material will be necessary to stabilize relationships within Gondwanatheria and to establish meaningful and reliable definitions of these clades. 


\section{Assumptions Concerning Tooth Homologies}

We follow tooth homology assumptions laid out in the Supplementary Information sections of Krause et al. $(2014,2020)$. Here we review those assumptions most relevant to scorings of Adalatherium. In general, we provisionally assume, in the absence of contradictory information, that incisors and molars are lost from the distal ends of tooth series (Ziegler, 1971; Luckett, 1993). The mesial and distal upper incisors (I) in Adalatherium are therefore scored as I1 and I2, respectively. However, derived multituberculates and some euharamiyidans do not appear to follow this pattern. Whereas basal multituberculates have three upper incisors, identified by most authors as I1, I2, and I3 (e.g., Clemens and Kielan-Jaworowska, 1979; Simmons, 1993; Kielan-Jaworowska and Hurum, 2001; Kielan-Jaworowska et al., 2004), more derived multituberculates (cimolodontans) have lost I1, leaving only I2 and I3. Similarly, although there is some controversy concerning upper incisor homologies, at least one euharamiyidan, Xianshou, appears to retain a reduced I1 along with an enlarged I2, whereas others (e.g., Arboroharamiya, Maiopatagium, Shenshou, and Vilevolodon; Mao et al., 2019) have lost the mesial upper incisor and retain only a single, large upper incisor, identified as I2 (Bi et al., 2014; Han et al., 2017; Luo et al., 2017; Meng et al., 2017; Mao et al., 2019).

We further follow the AToL Mammal Tree of Life coding strategy (O'Leary et al., 2013) that premolars are lost from the middle (p3/P3) of the series, and then mesially (p1/P1 or p2/P2). The penultimate and ultimate premolars are thus identified as $\mathrm{p} 4 / \mathrm{P} 4$ and $\mathrm{p} 5 / \mathrm{P} 5$, respectively. We extended this assumption to multituberculates, euharamiyidans, and Haramiyavia (Jenkins et al., 1997; Kielan-Jaworowska et al., 2004; Luo et al., 2015; Bi et al., 2014). 
If not explicitly stated otherwise, we scored molar characters based on the first or second positions ( $\mathrm{m} 1 / \mathrm{m} 2$ and $\mathrm{M} 1 / \mathrm{M} 2)$. Referring to a specific molar position is particularly problematic in basal cynodonts, as premolars and molars cannot be clearly distinguished based on either morphological criteria or replacement pattern (e.g., Crompton, 1963; Crompton and Jenkins, 1979; Gow, 1980, 1985; Luo et al., 2004; Martinelli and Bonaparte, 2011; Abdala et al., 2013). We therefore scored most premolar or molar characters referring to a specific premolar/molar position as inapplicable for Thrinaxodon, Probainognathus, Cynognathus, Diademodon, Exaeretodon, Pachygenelus, Brasilodon, and Riograndia. However, we scored molar characters for tritylodontids, in order to test relationships among multi-rowed teeth of tritylodontids, multituberculates, haramiyidans, euharamiyidans, and gondwanatherians.

As in the phylogenetic data set employed by Krause et al. (2020), we scored Sudamerica and Galulatherium as having one lower incisor, no canines, no lower premolars, and four lower molars, and Vintana as having two upper incisors, no canines, one upper premolar and four upper molars. The dental formula is unknown for Bharattherium, Ferugliotherium, Gondwanatherium, Greniodon, Lavanify, and Trapalcotherium. The morphology of the postcanines in Adalatherium is distinctly different from that of any other mammaliaform and cannot readily be homologized with any known dental pattern (Krause, Hu, et al., this volume). For scoring purposes, it is, however, necessary to make assumptions regarding the positional homology of the postcanines of Adalatherium. A morphological discontinuity is present in the upper dentition of Adalatherium: the mesial-most upper postcanine (PC1 in Krause, Hu, et al., this volume) is small, two-rooted, and peg-like and identified here as the ultimate premolar (P5), whereas the following four postcanines (PC2-PC5 in Krause, Hu, et al., this volume) differ from P5 in being much larger, having more than two roots, and displaying a complex cusp pattern. Thus, for 
scoring purposes, we identify the posterior upper postcanines as upper molars (M1-M4) in all analyses. Establishing homologies for the lower postcanines is more difficult (Krause, Hu, et al., this volume) and, as such, we scored Adalatherium assuming three different lower dental formulae. First, 'Adalatherium 1004' was scored as having no lower premolars and four molars, similar to the lower dental formula of Sudamerica and Galulatherium. In addition to specifically testing affiliations with Sudamerica and Galulatherium, this formula was chosen because it mirrors the number of molars in the upper jaw. Second, 'Adalatherium 1013' was scored as having one lower premolar and three molars. In support of this interpretation, a slight disruption in morphological gradient is visible between $\mathrm{pc} 1$ and pc2-pc4: pc1 is smaller and has two roots, compared to the numerous roots seen in more distal postcanines. In addition, $\mathrm{pc} 1$ has fewer cusps and lacks the mesiobuccal basin that is at least incipiently developed as a bulge on pc2 and fully developed on pc3 and pc4. 'Adalatherium 1013' is the coding scheme assumed by Krause et al. (2020). Third, 'Adalatherium 1022' was scored as having two premolars and two molars. The last two postcanines, pc3 and pc4, have a well-developed, rimmed, mesiobuccal basin, that is absent in pc1 and only incipiently developed in pc2. This dental formula assumes that Adalatherium has the same number of lower molars as multituberculates, namely two. However, we must note that a lower dental formula of two premolars and two molars stands in strong contrast to the upper dental formula of one premolar and four molars presumed here for Adalatherium. In mammaliaforms, the number of upper and lower molars are usually in better agreement, which might render this dental formula less likely than 'Adalatherium 1004' or 'Adalatherium 1013'.

\section{Data Sets}


Separate analyses were conducted for the three different lower dental formulae of Adalatherium: 'Adalatherium 1004' (i1 c0 p0 m4), 'Adalatherium 1013' (i1 c0 p1 m3) and 'Adalatherium 1022' (i1 c0 p2 m2), abbreviated in the following sections as 1004, 1013, and 1022, respectively. In addition, for some parsimony analyses, we constrained nodes within multituberculates to reflect the current consensus view of their relationships by forcing the Jurassic paulchoffatiids and Rugosodon to be at the base of Multituberculata, and Taeniolabis and Lambdopsalis to be sister to Djadochtatherioidea (see "Multituberculata" for more detailed review). The constrained tree is presented separately in the Supplementary Data 2).

Combinations of these different coding strategies led to a total of six parsimony analyses (Table 1). Given the time required to run the Bayesian analyses, we performed undated and tip-dated Bayesian analyses without topological constraints. In addition, relationships among multituberculates in the Bayesian analyses were in better accord with currently accepted relationships even when unconstrained. In the following section, the analyses will be listed as 1004, 1004_constraint, 1004_undated, 1004_dated; 1013, 1013_constraint, 1013_undated, 1013_dated; and 1022, 1022_constraint, 1022_undated, and 1022_dated, thus referring to the dental coding schemes used for Adalatherium (1004, 1013, and 1022), whether or not nodes within multituberculates were constrained (_constraint or blank), and type of analysis (blank or _constraint for parsimony, _undated for undated Bayesian, and _dated for tip-dated Bayesian) .

\section{Phylogenetic Methods}

Parsimony Analyses-The maximum parsimony analyses were performed in Tree Analysis using New Technology software package (TNT) version 1.1 (Goloboff et al., 2008). A traditional search algorithm (heuristic tree search) was conducted performing 10,000 replicates 
of Wagner trees using random addition sequence (RAS), followed by tree bisection and reconnection (TBR) branch swapping, holding 10 trees per replicate. The shortest trees obtained through this analysis were subjected to a final round of TBR branch swapping. Trees were rooted along the branch leading to Thrinaxodon. All characters were treated as equally weighted and unordered. Nelson strict consensus trees were calculated in TNT. Support for each node was assessed using Bremer values (also known as decay indices; Bremer, 1994). Bremer support was calculated for each node in TNT by retaining all trees suboptimal up to 10 steps longer than the shortest trees. README files for an exemplar analysis (1013) can be found in Supplementary Data 3. Ensemble consistency index (CI) and retention index (RI) values were calculated in Phylogenetic Analysis Using PAUP* 4.0a (PAUP) (Swofford, 2003). All most parsimonious trees (MPTs), as well as the strict consensus trees, are provided in Supplementary Data 4-10. Character optimization for the parsimony analyses was performed in PAUP* using the accelerated transformation (ACCTRAN) optimization criterion. Only unambiguous apomorphies are listed in Table 2; complete apomorphy lists for each analysis are provided in Supplementary Data 11-16. These lists, which are also excerpted below in the text, include autapomorphies in addition to synapomorphies.

Undated Bayesian Analyses-Undated Bayesian phylogenetic analyses of the 1004, 1013, and 1022 data sets were performed in MrBayes 3.2.7a (Ronquist et al., 2012) using the CIPRES Scientific Gateway web portal (Miller et al., 2010), and are herein referred to as 1004_undated, 1013_undated, and 1022_undated. We used Lewis' (2001) Markov (Mk) model for morphological data, with the assumption that only variable characters were scored (i.e., the $\mathrm{Mk} v$ variant), and an eight category lognormal distribution to model rate heterogeneity between characters (Harrison and Larson, 2015). Analyses were run for 10 million Markov Chain Monte 
Carlo (MCMC) generations, sampling every 5000 generations. Four runs were performed simultaneously, with four MCMC chains, three of which were heated (temp $=0.1$, which is the MrBayes default). Visual inspection of parameter values in Tracer 1.6 (Rambaut et al., 2014) indicated that stationarity and convergence between chains were achieved within 1 million generations (i.e., the first 10\%) in the analyses of all three data sets; with this burn-in period excluded, effective sample size (ESS) was $>200$ for all parameters, indicating sufficient sampling. The post-burn-in trees were summarized in MrBayes using 50\% majority-rule consensus trees (using the 'contype=halfcompat' command) and 50\% majority-rule consensus but retaining all compatible clades that occurred in $<50 \%$ of the trees (using the 'contype=allcompat' command). Maximum Clade Credibility (MCC) trees were also produced using TreeAnnotator v2.3.0 in the BEAST2 package (Bouckaert et al., 2019), using 'Common Ancestor' node heights, after first combining the post-burn-in trees from all four runs into a single file, using the perl script BurnTrees (available here:

https://github.com/nylander/Burntrees). Clade support was estimated using Bayesian posterior probabilities (PPs), with values between 0 and 0.25 considered 'very weakly supported,' between 0.26 and 0.50 'weakly supported,' between 0.51 and 0.75 'moderately supported,' and between 0.76 and 1.00 'strongly supported.' README files for the analyses can be found in Supplementary Data 3. Halfcompat, allcompat, and MCC trees are provided in Supplementary Data 17-19. Character optimization for the undated Bayesian analyses was performed on the MCC trees in PAUP* using the accelerated transformation optimization criterion, similarly to the parsimony analyses. Only unambiguous synapomorphies are listed in Table 3; complete synapomorphy lists for each analysis are provided in Supplementary Data 20-22.

Tip-dated Bayesian Analyses-Tip-dated Bayesian analyses used the same Mkv model 
plus eight category lognormal distribution employed in the undated analyses. An Independent Gamma Rates (IGR) clock model was used, assuming a normally distributed clock rate prior with a mean of 0.001 and standard deviation of 0.01 , and an exponential prior on the variance of the gamma distribution of the IGR model with a value of 10 (the MrBayes default). The position of the root was specified by enforcing monophyly of all taxa except Thrinaxodon. Ages of taxa were specified as either uniform distributions between maximum and minimum bounds, or (for those taxa where the age was very tightly constrained) as fixed-point estimates. The age of the root was constrained as a uniform distribution with a minimum age of 259.1 million years and maximum age of 272.9 million years, which corresponds to the middle Permian (Guadalupian). A fossilized birth-death prior was specified on the branch lengths ('clock:fossilization'), with diversity sampling and an assumed sampling fraction of 0.003 (four extant mammalian genera out of a total of approximately 1,258 currently recognized). We used the MrBayes default priors on speciation rate (exponential prior with a value of 10), and extinction and fossilization rates (in both cases, a "flat" beta prior with a mean and variance of 1). MCMC analyses were run for 10 million generations, with the same settings as for the undated analyses, and Tracer was again used to identify an appropriate burn-in period, which varied between 1 and 4 million generations (10 and 20\%), depending on the analysis. In each analysis, ESS values were $>100$ for all parameters, and $>200$ for most parameters, after exclusion of the burn-in period. As in the undated analyses, post-burn-in trees for each tip-dated analysis were summarized using 50\% majority-rule consensus and 50\% majority-rule consensus but retaining all compatible clades. After combining the post-burn-in trees using BurnTrees, MCC trees were again produced using TreeAnnotator v2.3.0, but with 'Median' node heights specified, as some of the post-burn-in trees included sampled ancestors. Posterior probability values between 0 and 0.25 will be 
considered 'very weakly supported,' between 0.26 and 0.50 'weakly supported,' between 0.51 and 0.75 'moderately supported,' and between 0.76 and 1.00 'strongly supported.' README files for the analyses can be found in Supplementary Data 3. Halfcompat, allcompat and MCC trees are provided in Supplementary Data 23-25. Character optimization for the undated Bayesian analyses was performed on the MCC trees in PAUP* using the accelerated transformation optimization criterion. Only unambiguous synapomorphies are listed in Table 3; complete synapomorphy lists for each analysis are provided in Supplementary Data 26-28.

\section{RESULTS}

\section{Parsimony Analyses}

The number of most parsimonious trees (MPTs), tree length, ensemble consistency index (CI), and ensemble retention index (RI) for each analysis are listed in Table 1. Simplified cladograms of the unconstrained (Fig. 1A, B) and constrained (Fig. 1C, D) parsimony analyses are shown in Figure 1. The strict consensus topologies are identical for the unconstrained 1013 and 1022 analyses, and for the constrained 1013_constraint and 1004_constraint analyses; as such, only the topologies for 1013 are shown in Figure 1A and C, respectively. The MPTs (Supplementary Data 4-9), strict consensus trees (Supplementary Data 10), and synapomorphy lists (Supplementary Data 11-16) for each parsimony analysis can be found in the Supplementary Data section. In all six parsimony analyses, Adalatherium falls within Gondwanatheria (Fig. 1). The topology within the gondwanatherian clade is identical in all three unconstrained analyses, but constraining nodes among multituberculates affected relationships within Gondwanatheria. In all but the 1022_constraint analysis, Gondwanatheria are recovered 
as sister to Multituberculata, and Gondwanatheria + Multituberculata are placed as sister to Euharamiyida within Allotheria. In all six analyses, Haramiyavia and Thomasia are not supported as members of Allotheria, but are instead placed as sister to Tritylodontidae + Megaconus, outside of Mammaliaformes.

Adalatherium - In all unconstrained analyses, Adalatherium is sister to a clade containing Galulatherium + Sudamericidae (here including Gondwanatherium, Greniodon, Sudamerica, Bharattherium, Lavanify, and Vintana) (Fig. 1A, B). In these analyses, Adalatherium is characterized by eight unambiguous apomorphies (Table 2), including presence of a septomaxillary foramen (char. 122), internasal vacuity (char. 131), large foramen in lacrimal (char. 146), rostral tympanic process (char. 252), and upper canines (char. 370). By contrast, in the constrained analyses (1013_constraint and 1004_constraint), Adalatherium is recovered as sister to Galulatherium in a polytomy with sudamericids (Fig. 1C). In these two analyses, Adalatherium and Galulatherium are united by the absence of transverse lophs (char. 417), absence of synclines or furrows (char. 419), and absence of islets or infundibula (char. 421) on their molars. Relationships within Gondwanatheria collapse in 1022_constraint, with Adalatherium placed in a polytomy with non-ferugliotheriid gondwanatherians.

Gondwanatheria - Gondwanatheria are a poorly supported node, with a Bremer value of 1 for all unconstrained analyses (Fig. 1A, B), and a Bremer value of 2 in the 1013_constraint and 1004_constraint analyses (Fig. 1C). In all but one analysis (1022_constraint), presence of a gliriform I1 (char. 359), and enamel covering of I1 restricted to buccal surface (char. 362) optimize as unambiguous synapomorphies of Gondwanatheria. In addition, in the unconstrained 1013 and 1022 analyses, lower molars with three or more roots (char. 459) is resolved as a synapomorphy of Gondwanatheria, whereas in the 1013_constraint and 1004_constraint 
analyses, lower i1 with restricted enamel (char. 368), presence of synclines or furrows (char. 419), and presence of islets or infundibula on molars (char. 421) are found to be synapomorphies. In all unconstrained analyses, the low-crowned Ferugliotherium and Trapalcotherium form a monophyletic Ferugliotheriidae (Fig. 1A, B), but Ferugliotheriidae are paraphyletic in the 1013_constraint and 1004_constraint analyses (Fig. 1C). Ferugliotherium and Trapalcotherium do not cluster with Gondwanatheria in the 1022_constraint analysis, but are instead resolved in a polytomy with multituberculates, the remaining gondwanatherians, euharamiyidans, and Cifelliodon (Fig. 1D). Sudamericidae are recovered in all unconstrained analyses, but resolution within the clade is poor. Vintana, Gondwanatherium, Sudamerica, Greniodon, and a clade containing Bharattherium and Lavanify are placed in a polytomy supported by presence of transverse lophs (char. 417), synclines or furrows (char. 419), and islets or infundibula (char. 421) on molars. Galulatherium is resolved as sister to Sudamericidae in the unconstrained analyses (Fig. 1A, B), whereas Galulatherium and Adalatherium are placed in a polytomy with sudamericids in the 1013_constraint and 1004_constraint analyses (Fig. 1C), although the MPTs reveal that Adalatherium + Galulatherium are always nested within Sudamericidae. The least resolved topology is recovered in the 1022_constraint analysis, with only Lavanify and Bharattherium forming a clade, and the remaining gondwanatherians (to the exclusion of ferugliotheriids) placed in a polytomy (Fig. 1D).

Multituberculata - The unconstrained parsimony analyses recover a rather unconventional topology for multituberculates relative to other studies, with the Paleogene Taeniolabis and Lambdopsalis placed at the base of Multituberculata, whereas the Jurassic paulchoffatiids are nested deeply within a monophyletic Plagiaulacida (Fig. 1A, B). This topology is driven partly (1) by the basal position of Euharamiyida within Allotheria, and (2) by 
similarities between Adalatherium and multituberculates that are generally considered derived in most recent studies (e.g., Smith and Codrea, 2015; Xu et al., 2015; Mao et al., 2016; Csiki-Sava et al., 2018; Wang et al., 2019). This combination of factors leads to a topology that optimizes morphological features that are currently considered to be characteristic of derived multituberculates as plesiomorphic for Multituberculata, and morphological features that are currently considered to be plesiomorphic as having evolved deeply nested within Multituberculata. For example, the number of upper premolars is optimized as 'one' at the base of Multituberculata and Gondwanatheria (based on the presence of a single upper premolar in Vintana, Adalatherium, Taeniolabis, and Lambdopsalis), but paulchoffatiids, eobaatariids, and plagiaulacids all have five upper premolars, which is generally assumed to be the plesiomorphic condition for Multituberculata (e.g., Kielan-Jaworowska et al., 2004). A likely convergent loss of premolars is here optimized as a plesiomorphic multituberculate trait. Similar examples include the shape of the incisors, number of cusps on the incisors, and the number of infraorbital foramina.

We therefore constrained relationships within multituberculates to match those recovered in most recent phylogenetic analyses that focus more specifically on multituberculates (e.g., Smith and Codrea, 2015; Xu et al., 2015; Mao et al., 2016; Csiki-Sava et al., 2018; Wang et al., 2019). Unsurprisingly, there is a rather drastic change in character support between the unconstrained and constrained analyses. In the unconstrained analyses, multituberculates are characterized by 17-19 synapomorphies, compared to 21 in the 1004_constraint and 1013_constraint analyses and 14 in the 1022_constraint analysis, but there are only five synapomorphies in common between the analyses, including reduced jugal (chars. 160, 162); two or more foramina for mandibular division of trigeminal nerve (char. 181); and absence of 
tabular (char. 292). The Bremer support is higher in the constrained analyses (only considering those nodes that were not constrained), with a value of $6-8$ for the Multituberculata node, and 5 for the Djadochtatherioidea node (Fig. 1C, D). Both nodes receive a Bremer value of 3 in the unconstrained analyses. In the unconstrained analyses, the Guimarota paulchoffatiids, Rugosodon, Plagiaulacidae, Sinobaatar, and Jeholbaatar form a monophyletic Plagiaulacida, whereas they are placed successively more basal to cimolodontans in the constrained analyses. Djadochtatherioidea are recovered in all analyses. In the unconstrained 1013 and 1022 analyses, Ptilodus is placed in a polytomy with Plagiaulacida and Djadochtatherioidea, but as sister to Djadochtatherioidea in the 1004 analysis (Fig. 1A, B).

Multituberculata + Gondwanatheria-Multituberculata and Gondwanatheria are recovered as sister taxa in all (Fig. 1A-C) but one analysis (1022_constraint, Fig. 1D). Support for the clade is low, with a Bremer value of 1 (Fig. 1). However, the clade is characterized by at least 15 unambiguous synapomorphies in the unconstrained analyses, eight of which are also recovered as synapomorphies in the constrained analyses. These include: presence of parafibula (char. 82), presence of nasal foramina (char. 128), absence of angular process on mandible (char. 325), and medial pterygoid ridge that reaches dentary condyle (char. 332, 333).

Allotheria - In all parsimony analyses, Allotheria include Euharamiyida, Multituberculata, Gondwanatheria, and Cifelliodon. Thomasia and Haramiyavia are recovered outside of Allotheria and Mammaliaformes, as sister to a clade containing Megaconus and Tritylodontidae (Fig. 1). The clade comprising Thomasia, Haramiyavia, Megaconus, and Tritylodontidae has a low Bremer support of 1 and is characterized by five synapomorphies: anteroventral margin of masseteric fossa on mandible forms low crest (char. 336), diastema distal to lower incisors (char. 355), upper postcanines much wider than lower postcanines (char. 
415), postcanines with multiple rows (char. 424), and dorsoposterior movement of dentary during power stroke (char. 521). In the unconstrained analyses, the Multituberculata + Gondwanatheria clade is recovered as sister to a monophyletic Euharamiyida, with Cifelliodon placed at the base of Allotheria (Fig. 1A, B). A similar typology is recovered in the 1013_constraint and 1004_constraint analyses (Fig. 1C). Basal relationships within Allotheria are unresolved in the 1022_constraint analysis, with Multituberculata, non-ferugliotheriid gondwanatherians, Ferugliotherium, Trapalcotherium, Euharamiyida, and Cifelliodon recovered in a polytomy (Fig. 1D). The Bremer support for the Allotheria node is low in all analyses, with a value of 1 . Allotheria are characterized by only seven unambiguous synapomorphies in the unconstrained analyses, and five or two synapomorphies in the constrained analyses. Two of these synapomorphies are common to both the unconstrained and constrained analyses: facial process of premaxilla contacting nasal (char. 117) and essentially flat glenoid (char. 192).

\section{Undated Bayesian Analyses}

Simplified cladograms of halfcompat topologies of the undated Bayesian analyses are shown in Figure 2; complete halfcompat, allcompat, and MCC trees (Supplementary Data 1719), as well as synapomorphy lists (Supplementary Data 20-22) for each analysis, can be found in the Supplementary Data section. The following discussion refers to the halfcompat topology shown in Figure 2. In all undated Bayesian analyses, Adalatherium is nested within Gondwanatheria (Fig. 2), which are nested within Multituberculata. Allotheria include euharamiyidans, multituberculates (including gondwanatherians), Thomasia, Haramiyavia, Megaconus, and Cifelliodon in the 1022_undated and 1004_undated analyses. Relationships collapse in the 1013_undated analysis: Multituberculata (including Gondwanatheria), 
euharamiyidans, Megaconus, Haramiyavia + Thomasia, eutriconodontans, and Trechnotheria are placed in a polytomy.

Adalatherium - The different coding schemes do not greatly impact the position of Adalatherium. In all undated Bayesian analyses, Adalatherium is nested with Gondwanatheria, either in a polytomy with all other gondwanatherians except Ferugliotherium and Trapalcotherium (1013_undated, 1022_undated; Fig. 2A, B) or as sister to Galulatherium (1004_undated; Fig. 2C). A close relationship with Galulatherium receives moderate support, with a posterior probability (PP) of 0.58 , and the clade is united by a series of molar features: absence of islets or infundibula (char. 417), absence of synclines or furrows (char. 419), and absence of transverse lophs (char. 421). Adalatherium is characterized by eight apomorphies in the 1013_undated analysis, and 11 synapomorphies in the 1022_undated analysis (Table 3), including presence of a septomaxillary foramen (char. 122), internasal vacuity (char. 131), foramen for $\mathrm{V}_{1}$ in lacrimal (char. 146), rostral tympanic process (char. 252), and upper canine (char. 370). Only five apomorphies optimize for Adalatherium in the 1004_undated analysis.

Gondwanatheria-Gondwanatheria are recovered in all analyses (Fig. 2) and are moderately supported $(\mathrm{PP}=0.63-0.75)$. Gondwanatheria are characterized by three synapomorphies in the 1022_undated and 1004_undated analyses (Table 3): presence of synclines or furrows on molars (char. 419), presence of transverse lophs on molars (char. 421), and distal aspect of molars closed by cuspules or ridge (char. 463). In all analyses, Gondwanatheria are nested deeply within Multituberculata as sister to Lambdopsalis and Taeniolabis (Fig. 2). This relationship is moderately supported with PPs of 0.65-0.76. Eleven synapomorphies unite this clade in the 1004_undated and 1022_undated analyses, and 12 in the 1013_undated analysis. Relationships within Gondwanatheria are largely unresolved. 
Ferugliotherium and Trapalcotherium are placed as sister to the remainder of Gondwanatheria, with Ferugliotherium as the first taxon to branch (1022_undated, 1004_undated; Fig. 2B, C), or with Ferugliotherium and Trapalcotherium placed in a polytomy with a clade comprising all other gondwanatherians (1013_undated; Fig. 2A). Relationships among the remaining gondwanatherians are largely unresolved in the 1013_undated (Fig. 2A) and 1022_undated analyses (Fig. 2B), with the exception that Bharattherium and Lavanify form a clade in both analyses ( $\mathrm{PP}=0.84-0.90)$. Gondwanatherium, Sudamerica, Bharattherium + Lavanify, Vintana, Galulatherium, Greniodon, and Adalatherium are clustered in a polytomy in these two analyses. In the 1004_undated analysis (Fig. 2C), Adalatherium and Galulatherium are sister taxa, as are Bharattherium and Lavanify, with Vintana, Bharattherium, and Lavanify forming a clade that is moderately supported $(\mathrm{PP}=0.51)$ and united by the presence of modified radial enamel (char. 517).

Multituberculata-Relationships within Multituberculata in the undated Bayesian analyses are in better agreement with current hypotheses than they are in the parsimony analyses, with the Jurassic Rugosodon and Guimarota Paulchoffatiidae placed at the base of Multituberculata, and Plagiaulacida recovered as paraphyletic but Cimolodonta as monophyletic (Fig. 2). Monophyly of Multituberculata (including Gondwanatheria) is strongly supported in most analyses, with PPs ranging from 0.84-0.96. Between five (1013_undated) and 13 (1022_undated) synapomorphies unite Multituberculata, with reduced jugal (chars. 160, 162) in common among the three different analyses. In contrast to the parsimony analyses, Gondwanatheria are placed within Multituberculata, as sister to Taeniolabis and Lambdopsalis. Allotheria_-In the 1022_undated and 1004_undated analyses, Allotheria encompass euharamiyidans, multituberculates (including gondwanatherians), Cifelliodon, and (in contrast to 
the parsimony analyses) Thomasia, Haramiyavia, and Megaconus (Fig. 2B, C). The allcompat topologies of these analyses reveal that there is moderate support ( $\mathrm{PP}=0.50-0.53)$ for placing Haramiyavia and Thomasia as sister to the remainder of Allotheria (Supplementary Data 17, 19). Allotheria are only moderately supported in the 1022_undated $(\mathrm{PP}=0.53)$ and 1004 _undated $(\mathrm{PP}=0.50)$ analyses, and collapse into a polytomy with several eutriconodontans and trechnotherians in the 1013_undated analysis (Fig. 2A). Allotheria are united by seven synapomorphies in the 1022_undated and 1004_undated analyses (Supplementary Data 20, 22). Basal relationships within Allotheria are largely unresolved in all three undated analyses, with Megaconus, Cifelliodon, Thomasia, Haramiyavia, euharamiyidans, and multituberculates placed in a polytomy. In the 1004_undated analysis, Euharamiyida are recovered as a clade that includes Arboroharamiya, Shenshou, Qishou, Vilevolodon, and Xianshou, but not Maiopatagium (Fig. 2C).

\section{Tip-dated Bayesian Analyses}

Simplified cladograms of halfcompat topologies of the tip-dated Bayesian analyses are shown in Figure 3; complete halfcompat, allcompat, and MCC trees (Supplementary Data 2325), as well as synapomorphy lists (Supplementary Data 26-29) for each analysis, can be found in the Supplementary Data section. The following discussion refers to the halfcompat topology shown in Figure 3. In all dated Bayesian analyses, Adalatherium is nested within Gondwanatheria (Fig. 3). Gondwanatheria + Cifelliodon are sister to euharamiyidans in the 1022_dated and 1013_dated analyses, but are placed in a polytomy with Multituberculata and Euharamiyida in the 1004_dated analysis. Similar to the parsimony analyses, Allotheria include Euharamiyida, Gondwanatheria, Multituberculata, and Cifelliodon, whereas Thomasia, 
Haramiyavia, and Megaconus are recovered outside of Mammaliaformes, in a clade with Tritylodontidae.

Adalatherium - The different coding schemes do not impact the position of Adalatherium. In all dated Bayesian analyses, Adalatherium is nested within Gondwanatheria as sister to Sudamericidae (Fig. 3). A sister-group relationship with Sudamericidae is moderately supported $(\mathrm{PP}=0.59-0.61)$, and the clade is united by a dorsally positioned mental foramen on the dentary (char. 320). Adalatherium is characterized by eight apomorphies in the 1013_dated and 1022_dated analyses and seven apomorphies in the 1004_dated analysis (Table 3). Apomorphies in common to all dated analyses include: presence of septomaxillary foramen (char. 122), internasal vacuity (char. 131), foramen for $\mathrm{V}_{1}$ in lacrimal (char. 146), and rostral tympanic process (char. 252).

Gondwanatheria - Gondwanatheria (here excluding the ferugliotheriids Ferugliotherium and Trapalcotherium) are recovered in all analyses (Fig. 3), and the clade is strongly supported, with a PP of 1. Despite the high PP values, no unambiguous synapomorphies optimize as supporting this clade in 1013_dated and 1004_dated. Interestingly, in all dated Bayesian analyses, Ferugliotheriidae are placed outside of Gondwanatheria and are deeply nested within Multituberculata, as sister to Taeniolabidoidea. Placement of Ferugliotheriidae within Multituberculata is moderately supported with PPs ranging between 0.56 and 0.58 . Three synapomorphies unite Ferugliotheriidae with Taeniolabidoidea: presence of three or fewer lower postcanines (char. 377), buccal cingulid on p5 (char. 405), and mesiobuccal exodaenodont lobe on p5 (char. 412). This placement is therefore strongly influenced by the assumption that the dentary fragment containing a laterally compressed ultimate premolar is correctly assigned to Ferugliotherium (Kielan-Jaworowska and Bonaparte, 1996). In contrast to the parsimony and 
undated Bayesian analyses, relationships within Gondwanatheria are resolved in the dated Bayesian analyses (Fig. 3). Sudamericidae are recovered as sister to Adalatherium and are strongly supported, with PPs ranging from 0.85-0.89. Presence of islets or infundibula (char. 417), synclines or furrows (char. 419), and transverse lophs (char. 421) on molars unite Sudamericidae. In all dated analyses, Sudamericidae are divided into two clades: Sudamerica, Gondwanatherium, and Greniodon form a South American grouping that is sister to a clade containing the Indo-Madagascan genera Vintana, Bharattherium, and Lavanify. The South American clade is strongly supported, with PPs of $0.83-0.84$, but no synapomorphies optimize for this clade. The Indo-Madagascan clade is moderately supported (PPs $=0.52-0.56)$ and united by a single synapomorphy: modified radial enamel (char. 517). In all dated analyses, Galulatherium is recovered at the base of Gondwanatheria as sister to Adalatherium + Sudamericidae (Fig. 3). Furthermore, in all analyses, Cifelliodon is recovered as sister to Gondwanatheria, although with mixed support $(\mathrm{PP}=0.77$ and 0.78 in the 1013 dated and 1004_dated analyses, respectively, but 0.9 in the 1022_dated analysis).

Multituberculata-Similar to the undated Bayesian analyses, relationships within Multituberculata are in better agreement with current hypotheses than those found in the parsimony analyses, with the Jurassic Guimarota Paulchoffatiidae and Rugosodon placed at the base of Multituberculata, a paraphyletic Plagiaulacida, and a monophyletic Cimolodonta (but which here includes Ferugliotheriidae) (Fig. 3). Multituberculata are strongly supported in most analyses with PPs ranging between 0.88 and 0.99. Twelve (1013_dated, 1022_dated) or eight (1004_dated) synapomorphies unite Multituberculata, with seven synapomorphies in common among the three different analyses, including absence of septomaxilla (char. 119), presence of five upper premolars (char. 381), and M2 lingually offset relative to M1 (char. 514). In contrast 
to the parsimony analyses and undated Bayesian analyses, the ferugliotheriids Ferugliotherium and Trapalcotherium are placed within Multituberculata as sister to Taeniolabis and Lambdopsalis (Fig. 3).

Allotheria - In all dated Bayesian analyses, Allotheria form a clade that includes euharamiyidans, multituberculates, gondwanatherians, and Cifelliodon. Similar to the parsimony analyses, and in contrast to the undated Bayesian analyses, Thomasia + Haramiyavia are sister to Tritylodontidae + Megaconus and outside of Mammaliaformes (Fig. 3). The clade comprising Thomasia, Haramiyavia, Megaconus, and Tritylodontidae is moderately supported (PP 0.690.74 ) and characterized by the same five synapomorphies as in the parsimony analyses.

Allotheria are united by a high number of synapomorphies in the 1004_dated (18), 1013_dated (17), and 1022_dated (17) analyses, with 13 synapomorphies in common between the three analyses. The clade is strongly to moderately supported with PPs of 0.86 (1013_dated), 0.77 (1022_dated), and 0.69 (1004_dated). Relationships at the base of Allotheria are more resolved than in the undated Bayesian analyses. Cifelliodon + Gondwanatheria are recovered as sister to Euharamiyida in the 1022_dated analysis $(\mathrm{PP}=0.56)$ and in a polytomy with euharamiyidans in the 1013_dated analysis $(\mathrm{PP}=0.64)$. Five synapomorphies support a sistergroup relationship of euharamiyidans and Cifelliodon + Gondwanatheria in the 1013_dated and 1022_dated analyses, including scaphoid twice the size of lunate (char. 51), straight dorsal margin of ischium (char. 60), and presence of tabular bone (char. 292). Euharamiyida, including Arboroharamiya, Shenshou, Qishou, Vilevolodon, Xianshou, and Maiopatagium, are recovered as monophyletic in the 1022_dated and 1004_dated analyses, but not in the 1013_dated analysis.

\section{DISCUSSION}




\section{Adalatherium}

Adalatherium is recovered within Gondwanatheria in all analyses, independent of lower dental formula coding scheme or method of phylogenetic inference. None of the apomorphies are common to all analyses, but presence of septomaxillary foramen (char. 122), internasal vacuity (char. 131), lacrimal foramen on edge of orbit (char. 144.0), foramen for $\mathrm{V}_{1}$ in lacrimal (char. 146), rostral tympanic process (char. 252), and unique occlusal pattern (char. 520) have been recovered in nine of the 12 analyses. In addition to the apomorphies listed here, Krause et al. (2020:Supplementary Information Part G) and Krause, Groenke, et al. (this volume) provided a complete list of traits that diagnose Adalatherium. Several features shared or possibly shared with Vintana are discussed below.

The placement of Adalatherium within Gondwanatheria varies between different analyses, with Adalatherium either being placed as sister to Sudamericidae + Galulatherium (all unconstrained parsimony, Fig. 1A, B), sister to Sudamericidae (all tip-dated Bayesian, Fig. 3), sister to Galulatherium (1013_constraint, 1004_constraint, Fig. 1C; 1004_undated, Fig. 2C), or in a polytomy with gondwanatherians except for Ferugliotherium and Trapalcotherium (1022_constraint, Fig. 1D; 1013_undated and 1022_undated, Fig. 2A, B).

Interestingly, a sister-group relationship with the contemporary Madagascan Vintana was not recovered in any of the analyses except for the MCC of 1022_undated (Supplementary Data 19), despite the fact that Adalatherium and Vintana share several cranial and dental traits that are only rarely (or not at all) seen in other Mesozoic mammaliaforms. These include (1) presence of a septomaxilla with large intranarial process (chars. 119, 120); (2) large facial process of lacrimal (char. 142), contacting septomaxilla and excluding frontal and nasal from contact with maxilla 
(char. 143); (3) secondary bony canal in inner ear that parallels cochlear ganglion canal and likely enclosed vascular network (char. 221); as well as possibly shared features such as (4) thin, single-layered primary osseous lamina in inner ear that lacked habenulae perforatae, with cochlear nerve branches presumably passing along surface of osseous lamina (char. 219); and (5) two large and curved upper incisors (chars. 359, 360; the upper incisors of Vintana are not preserved but similarities in alveolar morphology between the two taxa indicate that this feature is shared) (Krause et al., 2020; Hoffmann and Kirk, this volume; Krause, Hoffmann et al., this volume; Krause, Hu et al., this volume). Vintana and Adalatherium are the only gondwanatherians represented by cranial material, and whether these features are unique to Vintana and Adalatherium or shared with other gondwanatherians is currently unknown.

Based on the many autapomorphic features of Adalatherium, Krause et al. (2020) established a new family within Gondwanatheria: Adalatheriidae. Most tree topologies recovered here are congruent with placing Adalatherium into its own family. In all tip-dated Bayesian and unconstrained parsimony analyses, Adalatherium is placed outside of both Sudamericidae and Ferugliotheriidae, warranting the recognition of a new family. In all undated Bayesian analyses the relationships within Gondwanatheria are poorly resolved, and Adalatherium is placed in a polytomy with various sudamericids. Of these undated analyses, the allcompat and MCC trees place Adalatherium within Sudamericidae in the 1004_undated analysis and outside of Sudamericidae in the 1013_undated analysis (Supplementary Data 17, 18). The relationships within Gondwanatheria are likewise unresolved in the 1022_constraint parsimony analysis, with 16 of the MPTs placing Adalatherium within Sudamericidae and 24 outside (Supplementary Data 9). In contrast, in all of the 16 MPTs of the 1004_constraint and 1013_constraint analyses Adalatherium + Galulatherium are placed within Sudamericidae (Supplementary Data 5, 7). 
Nevertheless, we consider that the establishment of a new family for Adalatherium seems justified based on available evidence, but requires further testing via the discovery of more complete skeletal material of other gondwanatherians.

\section{Gondwanatheria}

Gondwanatheria, including ferugliotheriids, are recovered in all parsimony analyses (except 1022_constraint; Fig. 1) and all undated Bayesian analyses (Fig. 2). In contrast, in the tip-dated Bayesian analyses, the ferugliotheriids Ferugliotherium and Trapalcotherium are nested within Multituberculata, as sister to Taeniolabidoidea. The character support for Gondwanatheria remains low and inconsistent across analyses, ranging between zero synapomorphies (dated Bayesian) to five synapomorphies (constrained parsimony). Most commonly, Gondwanatheria are supported by two unambiguous dental synapomorphies: (1) presence of furrows/synclines on molars (char. 419) and (2) presence of transverse lophs on molars (char. 421), both of which were also recovered as gondwanatherian synapomorphies in Krause et al. (2014). In addition, presence of a first upper gliriform incisor (char. 359), and enamel restricted to buccal surface of first upper incisor (char. 362) optimize as gondwanatherian synapomorphies in most parsimony analyses. On balance, and as a working hypothesis, we consider Gondwanatheria to include Sudamericidae (Bharattherium, Gondwanatherium, Greniodon, Lavanify, Sudamerica, and Vintana), Adalatheriidae (Adalatherium), and Galulatherium as Gondwanatheria incertae sedis. We consider it uncertain whether Ferugliotheriidae are members of Gondwanatheria.

The position of Ferugliotheriidae is contentious, and affiliations with Multituberculata have been suggested multiple times. Bonaparte (1986a) originally described Ferugliotherium 
based on an isolated molar, and tentatively placed the newly established family Ferugliotheriidae within Multituberculata. Bonaparte (1990) and Krause et al. (1992) reaffirmed the placement of Ferugliotherium within Multituberculata based on additional specimens. Later, Krause and Bonaparte (1993) proposed close ties between Ferugliotheriidae and Sudamericidae based on molar wear patterns, incisor morphology, enamel microstructure, and inferred jaw motion and placed both families within the superfamily Gondwanatherioidea, within the order Multituberculata. Particularly relevant for the placement of Ferugliotheriidae is a partial dentary with a blade-like ultimate lower premolar that was assigned to ?Ferugliotherium by KielanJaworowska and Bonaparte (1996). To date, no other gondwanatherian is known to have a bladelike lower premolar. The dentaries of Sudamerica and Galulatherium suggest the presence of four hypsodont postcanines, which we identified as molars for scoring purposes. Under this assumption, Sudamerica and Galulatherium completely lack premolars. Alternative interpretations of dental homologies have been presented by Gurovich (2006). Regardless of which dental loci they represent, none of the postcanines is blade-like. Adalatherium likewise possesses four lower postcanines of uncertain affinity, but, even if the first or second postcanines are homologized with premolars, none of them is blade-like.

Kielan-Jaworowska et al. $(2004,2007)$ excluded the dentary fragment with its blade-like premolar from Ferugliotherium and assigned it to Multituberculata incertae sedis. Rougier et al. (2009) criticized the reassignment and suggested that the blade-like premolar and a newly published bladed premolar of Argentodites both likely belong to ferugliotheriids. Furthermore, Rougier et al. (2009) argued that ferugliotheriids are either multituberculates or closely related to multituberculates. A similar conclusion was reached by Gurovich and Beck (2009), who included the blade-like premolar as part of their scorings for Ferugliotherium. Ferugliotherium 
was resolved in a polytomy with Sudamericidae and cimolodontan and 'plagiaulacidan' multituberculates in the phylogenetic analysis of Gurovich and Beck (2009), supporting placement of Ferugliotherium within, or sister to, Multituberculata. Krause et al. (2014) recovered a paraphyletic Ferugliotheriidae when either scoring Ferugliotherium based on molars only (Ferugliotherium A) or based on incisor, premolars, and molars (Ferugliotherium B). In the parsimony analyses of Krause et al. (2014), Ferugliotherium (A or B) was placed at the base of Gondwanatheria outside of Multituberculata, whereas in the undated Bayesian analysis Ferugliotherium B was recovered in a polytomy with gondwanatherians, multituberculates, and Arboroharamiya, but Trapalcotherium was still placed within Gondwanatheria. In other words, inclusion of the bladed premolar did not impact the position of Ferugliotherium in the parsimony analyses, whereas the position of Ferugliotherium was ambiguous in the undated Bayesian analysis of Krause et al. (2014).

In our analyses, which included the bladed premolar for Ferugliotherium, Ferugliotheriidae are either monophyletic and placed at the base of Gondwanatheria (all unconstrained parsimony analyses), paraphyletic and placed at the base of Gondwanatheria (1013_constraint, 1004_constraint, all undated Bayesian analyses), monophyletic and placed within Multituberculata (all dated Bayesian analyses), or possibly paraphyletic and placed in a polytomy with other allotherians (1022_constraint). Placement of the enigmatic ferugliotheriids will likely not be fully resolved until more complete specimens (in particular, with associated premolars and molars) are found and included in phylogenetic analyses.

The composition of Sudamericidae is ambiguous based on the analyses presented here. Sudamericidae was first established by Scillato-Yané and Pascual (1984) to include Sudamerica, based on a single hypsodont molar. Subsequently, the South American Gondwanatherium, 
Madagascan Lavanify and Vintana, and Indian Bharattherium were referred to Sudamericidae (Krause and Bonaparte, 1993; Krause et al., 1997, 2014; Prasad et al., 2007; Wilson et al., 2007). In addition, Krause et al. (2014) recovered Greniodon and Galulatherium (at the time referred to as "unnamed Tanzanian taxon") in a polytomy with the other sudamericids described to date and included them within the family. As a working hypothesis, we are here referring to the last common ancestor of Vintana and Sudamerica and their descendants as Sudamericidae. Using this definition, the unconstrained parsimony and tip-dated Bayesian analyses recovered Sudamericidae to include Gondwanatherium, Greniodon, Sudamerica, Vintana, Lavanify, and Bharattherium. In the better resolved tip-dated Bayesian analyses, Sudamericidae are divided into a monophyletic South American clade of Gondwanatherium, Sudamerica, and Greniodon, and an Indo-Madagascan grouping of Vintana, Lavanify, and Bharattherium. In contrast, most sudamericids are placed in a polytomy in the parsimony analyses (but with Bharattherium and Lavanify as sister taxa).

Most of our analyses favor placement of Greniodon within Sudamericidae. Goin et al. (2012) originally did not assign Greniodon to either Sudamericidae or Ferugliotheriidae, but it was placed in a polytomy with all other sudamericids and included in Sudamericidae by Krause et al. (2014). Our tip-dated Bayesian and unconstrained parsimony analyses support placement of Greniodon within Sudamericidae, whereas Greniodon is excluded from sudamericids in the tree topology of the 1004_constraint and 1013_constraint analyses. Furthermore, most of our analyses favor exclusion of Galulatherium from Sudamericidae. Galulatherium was recovered in a polytomy with other sudamericids in Krause et al. (2014), and tentatively assigned to Sudamericidae by Krause et al. (2014) and O'Connor et al. (2019). The latter ultimately concluded (p. 81) that "the support values for Sudamericidae are low and, largely for that reason, 
we prefer to conservatively refer to Galulatherium as ?Gondwanatheria due to the fact that gondwanatherians as a group remain poorly known.” In our tip-dated Bayesian analyses, Galulatherium is recovered as sister to Adalatherium + Sudamericidae, and in the unconstrained parsimony analyses as sister to Sudamericidae. In contrast, Galulatherium is placed within Sudamericidae in all MPTs of the 1004_constraint and 1013_constraint parsimony analyses. A grouping of Indo-Madagascan taxa (Vintana, Lavanify, and Bharattherium) within Sudamericidae was recovered in the Bayesian analyses of Krause et al. (2014:figs. S2, S4), and is also recovered in all of our tip-dated Bayesian analyses and one undated Bayesian analysis (1004), whereas a sister-group relationship between Bharattherium and Lavanify is recovered in all analyses.

In contrast to the unconstraint parsimony and tip-dated Bayesian analyses, in the undated Bayesian and 1022_constraint parsimony analyses, non-ferugliotheriid gondwanatherians are recovered in a polytomy, which ultimately leaves the composition of Sudamericidae ambiguous. As such, even though we tentatively identified Sudamericidae as the clade containing Vintana and Sudamerica, we want to caution that relationships within Gondwanatheria vary or are unresolved in our analyses. More stable and repeatedly recovered topologies are necessary to establish a robust phylogenetic definition of Sudamericidae.

Gondwanatheria are placed as sister to Multituberculata (unconstrained parsimony, 1013_constraint, 1004_constraint), nested within Multituberculata (undated Bayesian), as sister to Cifelliodon and closely related to Euharamiyida (dated Bayesian), or are unresolved in a polytomy with other allotherians (1022_constraint). Close affiliations between Gondwanatheria and Multituberculata have been frequently proposed, often with gondwanatherians (as a family or suborder) nested within Multituberculata (e.g., Krause et al., 1992; Krause and Bonaparte, 
1993; Kielan-Jaworowska and Bonaparte, 1996; Gurovich and Beck, 2009). Pascual et al. (1999) challenged the placement of gondwanatherians within Multituberculata, based on the dentary of Sudamerica with four hypsodont molars, and regarded Gondwanatheria as Mammalia incertae sedis (likely the clade that we here refer to as Mammaliaformes), a conclusion that was also accepted by Kielan-Jaworowska et al. (2004). Pascual and Ortiz-Jaureguizar (2007) later proposed that Gondwanatheria are sister to Multituberculata within Allotheria.

Phylogenetic analyses including Gondwanatheria are rare (Gurovich and Beck, 2009; Krause et al., 2014; Hoffmann, 2016) and often limited to the inclusion of Vintana (Luo et al., 2015; Han et al., 2017; Huttenlocker et al., 2018; King and Beck, 2019; Wang et al., 2019; Zhou et al., 2019). Gurovich and Beck (2009) recovered the gondwanatherians Ferugliotherium and Sudamerica + Gondwanatheria in a polytomy with "plagiaulacidan" and cimolodontan multituberculates. As a result, Gurovich and Beck (2009) included Gondwanatheria and Multituberculata within Allotheria, but could not resolve whether Gondwanatheria are nested within Multituberculata or are sister to the latter. Krause et al. (2014:figs. S2) recovered Gondwanatheria as nested within Multituberculata in their undated Bayesian analysis (similar to our undated Bayesian analyses), but as sister to Arboroharamiya (the only euharamiyidan included by Krause et al., 2014:figs. 3, S1, S3), in their parsimony analyses. The latter result is reminiscent of the topology recovered in our dated Bayesian analyses. Several more recent Mesozoic mammaliaform matrices have included the cranium of Vintana as the sole representative of Gondwanatheria. In Huttenlocker et al. (2018), Vintana was resolved as sister to Cifelliodon + Hahnodon within Euharamiyida (referred to as 'Eleutherodontida'), which fell outside of Mammalia. A similar topology was also recovered in the parsimony analysis of Zhou et al. (2019) and in the tip-dated Bayesian analysis of King and Beck (2019). A close relationship 
with Cifelliodon is also recovered in our tip-dated Bayesian analyses, with Cifelliodon placed as sister to Gondwanatheria. In contrast, Vintana was placed outside of Allotheria, as sister to Trechnotheria, in the Bayesian and parsimony analyses of Han et al. (2017:ED fig. 8) and the parsimony analyses of Wang et al. (2019), whereas Vintana was recovered as sister to Haramiyida (including Euharamiyida) in the Bayesian analysis of Wang et al. (2019).

\section{Multituberculata}

Multituberculata are recovered as monophyletic in all analyses, either as sister to Gondwanatheria (all parsimony analyses, with the exception of the 1022_constraint analysis), sister to all other allotherians (tip-dated Bayesian), or in a polytomy with other allotherians but with Gondwanatheria nested within Multituberculata (undated Bayesian). Multituberculata are strongly supported with high Bremer values $(>3)$, high posterior probabilities $(>0.84)$, and 5-21 synapomorphies depending on the type of analyses. Surprisingly, the unconstrained parsimony analyses led to a rather unconventional tree topology for multituberculates, with the Paleogene Taeniolabidoidea placed as the most basal taxon and the Late Jurassic Paulchoffatiidae deeply nested within Multituberculata.

Although relationships within multituberculates have been historically difficult to sort, more recent phylogenetic analyses have recovered relatively well-resolved tree topologies that are largely congruent. Initial parsimony analyses by Simmons $(1993 ; 49$ taxa and 67 cranial and dental characters), Rougier et al. (1997; 50 taxa and 67 cranial and dental characters), and Kielan-Jaworowska and Hurum (2001; 32 taxa and 62 cranial, mandibular, and dental characters) produced strict consensus trees that were not well resolved and "did not provide meaningful results" (Kielan-Jaworowska and Hurum, 2001:390). More recent phylogenetic treatments of 
multituberculates, focusing on cranial, mandibular, and dental characters, have been more successful in resolving relationships. These include Yuan et al. (2013; 41 taxa and 102 characters), Xu et al. (2015; 43 taxa and 102 characters), Mao et al. (2016; 43 taxa and 102 characters), Csiki-Sava et al. (2018; 46 taxa and 107 characters), Wang et al. (2019; 51 taxa and 130 characters) focusing on multituberculate relationships in general, and Rougier et al. (2016; 17 taxa and 44 characters) and Wible et al. (2019; 18 taxa and 74 characters) focusing on relationships within Cimolodonta specifically. In all of these recent analyses, the Guimarota paulchoffatiids and Rugosodon are placed at the base of Multituberculata, with a paraphyletic Plagiaulacida and a monophyletic Cimolodonta (including Taeniolabidoidea, Ptilodus, and Djadochtatherioidea) deeply nested within multituberculates.

Not only are the multituberculate relationships within our unconstrained parsimony analyses contrary to the current consensus view, but the recurrent recovery of a monophyletic Plagiaulacida (including the Guimarota Paulchoffatiidae, Plagiaulacidae, Rugosodon, Jeholbaatar, and Sinobaatar) is noteworthy. In addition to the recent multituberculate matrices listed above, paraphyly of Plagiaulacida was recovered by Simmons (1993) and was also suggested by Kielan-Jaworowska and Hurum (2001). In many earlier analyses of mammaliaform relationships (e.g., Luo et al., 2002, 2007; Rougier et al., 2007; Gurovich and Beck, 2009), 'plagiaulacidans' were grouped and scored as a single taxonomic unit and, as such, the monophyly or paraphyly of this group could not be tested within a broader sample of mammaliaforms. In more recent studies, 'plagiaulacidans' have been split into the paulchoffatiid Kuehneodon, Rugosodon, plagiaulacids, and the eobaatarid Sinobaatar, and these taxa have been successively placed at the base of Multituberculata (e.g., Yuan et al., 2013; Zhou et al., 2013; Bi et al., 2014; Krause et al., 2014; Han et al., 2017; Huttenlocker et al., 2018; as well as in our 
Bayesian analyses). It should be noted that, similar to the result recovered in the unconstrained parsimony analyses of this study, Plagiaulacida (including Sinobaatar, plagiaulacids, Kuehneodon and Rugosodon), were also recovered as monophyletic by Luo et al. (2015:fig. 4). We believe that the unusual topology recovered in our parsimony analysis is driven by derived features that are shared by Taeniolabidoidea and Adalatherium but that are almost certainly homoplastic between the two. Because of the current weight of evidence (including our undated and tip-dated Bayesian analyses) that this topology is incorrect, we conducted additional parsimony analyses constraining relationships within Multituberculata to match the current consensus view. The effect of this on the support of Multituberculata was drastic.

Multituberculata have a Bremer value of 8 and 6 in the constrained analyses but only 3 in the unconstrained. As noted above, the Bayesian analyses recovered relationships within Multituberculata that are in better agreement with the current consensus view, except for the placement of Gondwanatheria (undated Bayesian) or Ferugliotheriidae (tip-dated Bayesian) as sister to Taeniolabidoidea.

\author{
Allotheria \\ The composition of Allotheria differs between our parsimony and dated Bayesian \\ analyses on the one hand, and the undated Bayesian analyses on the other. In the parsimony and \\ dated Bayesian analyses, Haramiyavia, Thomasia, and Megaconus are placed outside of \\ Allotheria and Mammaliaformes, and grouped with Tritylodontidae. In the undated Bayesian \\ analyses, these three taxa are placed in a polytomy with other allotherians. \\ The composition of Allotheria has been contentious ever since it was established by \\ Marsh (1880), and such remains the case in recent analyses (Fig. 4). Initially, Marsh (1880:239)
}


only included the two Late Jurassic multituberculates Plagiaulax and Ctenacodon within Allotheria, which he considered to be characterized by (1) low number of teeth, (2) absence of canines, (3) premolar and molar teeth "specialized," (4) angle of lower jaw distinctly inflected, and (5) absence of mylohyoid groove. At various points, tritylodontids were included in Multituberculata or Allotheria (e.g., Cope, 1884; Broom, 1914; Simpson, 1929), but Simpson (1945) raised Allotheria to a subclass with a single order Multituberculata, and excluded Tritylodontidae from Multituberculata and Allotheria, as had previously been suggested by, for example, Seeley (1894) and Watson (1942). Hahn (1973) first included the suborder Haramiyoidea within Multituberculata, which was tentatively accepted by Lillegraven et al. (1979). Hahn et al. (1989) later raised Haramiyoidea to ordinal status, as Haramiyida, and included it with Multituberculata and Theroteinida in Allotheria. With the description of Haramiyavia, Jenkins et al. (1997) questioned the affiliation between Haramiyida and Multituberculata, and excluded Haramiyida from Allotheria. Butler and MacIntyre (1994) and Butler (2000) regarded Haramiyida (including Theroteinus, Haramiyavia, Thomasia, Allostaffia, and Eleutherodon) as sister to Multituberculata and assigned them to Allotheria, a conclusion followed by Kielan-Jaworowska et al. (2004). Pascual and Ortiz-Jaureguizar (2007) suggested that Gondwanatheria be placed within Allotheria as sister to Multituberculata, which was subsequently supported by Gurovich and Beck (2009) and Krause et al. (2014, 2020).

In recent years, seven taxa that are particularly relevant to understanding the composition and phylogenetic relationships of Allotheria have been described, all of them based on fairly complete specimens from China. These include Megaconus (Zhou et al., 2013), Arboroharamiya (Zheng et al., 2013; Meng et al., 2014; Han et al., 2017), Shenshou (Bi et al., 2014), Xianshou (Bi et al., 2014), Vilevolodon (Luo et al., 2017), Maiopatagium (Meng et al., 2017), and Qishou 
(Mao and Meng, 2019). In various analyses, combinations of these taxa have either been placed within Allotheria as part of Euharamiyida (as sister to Multituberculata), or outside of Mammalia and separate from Multituberculata as members of Haramiyida, Euharamiyida, Eleutherodonta, Eleutherodontida, or Eleutherodontidae (see Fig. 4 and more detailed discussion on 'Haramiyida, Euharamiyida, and Eleutherodonta' below).

At the heart of the discussion is how Allotheria are defined. Luo et al. (2002) and KielanJaworowska et al. (2004) defined Allotheria as Multituberculata and Haramiyida, but the inclusion of Haramiyida within Allotheria has been questioned before (e.g., Jenkins et al., 1997). Indeed, the mandible of Haramiyavia lacks most of the characteristic features of Allotheria originally listed by Marsh (1880), such as low number of teeth, "specialized" premolars, absence of canines, and a distinctly inflected angle of the lower jaw. Sereno (2006) defined Allotheria as the most inclusive clade containing Taeniolabis but not Ornithorhynchus or Mus. Following this phylogenetic definition and trees resulting from our analysis, Allotheria includes Multituberculata, Gondwanatheria, Cifelliodon, and Euharamiyida (Shenshou, Xianshou, Arboroharamiya, Vilevolodon, Maiopatagium, and Qishou) but, in most of our analyses, not Haramiyavia, Thomasia, or Megaconus. Haramiyavia and Thomasia form a clade in all of our analyses, which we here confirm to be part of Haramiyida.

\section{Haramiyida, Euharamiyida, and Eleutherodonta}

Our analyses recover a monophyletic Haramiyida, represented by the haramiyaviid Haramiyavia and the haramiyid Thomasia, as sister to Tritylodontidae + Megaconus outside of Mammaliaformes (parsimony, tip-dated Bayesian), or in a polytomy with other allotherians within Mammalia (undated Bayesian). Haramiyida, which was elevated to the rank of order by 
Hahn et al. (1989), originally included Thomasia and Haramiya (later synonymized with Thomasia by Butler and MacIntyre, 1994), based on isolated teeth from the Late Triassic of Europe (Butler and MacIntyre, 1994 and references therein). Butler (2000) revised Haramiyida and included (1) Thomasia; (2) Theroteinus, based on isolated teeth from the Late Triassic of Europe (originally assigned to Haramiyidae by Sigogneau-Russell et al. [1986], but placed into the order Theroteinida by Hahn et al. [1989]); (3) Eleutherodon, based on an isolated tooth from the Middle Jurassic of Europe (originally referred to Eleutherodontida and placed in Allotheria by Kermack et al. [1998]); (4) questionably, Allostaffia, based on an isolated tooth from the Late Jurassic of Africa (Heinrich, 1999, 2004); and (5) Haramiyavia, based on teeth, mandibular, premaxillary, maxillary, and postcranial elements from the Late Triassic of Greenland (Jenkins et al., 1997). Additional isolated teeth have since been added to Allostaffia (Heinrich, 2001) and Eleutherodon (Butler and Hooker, 2005). Subsequently, but before 2013, several other taxa currently known only from isolated teeth have been referred to Haramiyida, in some cases tentatively; these include Sineleutherus from the Middle Jurassic of Russia and China, Kirtlingtonia and Millsodon from the Middle Jurassic of the U.K., Avashishta from the Late Cretaceous of India, Hahnodon and Denisodon from the Early Cretaceous of Morocco, and Mojo from the Late Triassic of Belgium (Butler and Hooker, 2005; Maisch et al., 2005; Anantharaman et al., 2006; Martin et al., 2010; Averianov et al., 2011; Bi et al., 2014; Huttenlocker et al., 2018). Most of these studies have placed Haramiyida within Allotheria and within Mammalia, although several phylogenetic analyses have previously recovered Haramiyavia in a more basal position outside of Mammaliaformes (e.g., Luo et al., 2002; Rougier et al., 2007; Gurovich and Beck, 2009).

Since 2013, fairly complete mammaliaform specimens from the Middle to Late Jurassic 
of China have been described and variously placed within Haramiyida, Eleutherodonta, Eleutherodontida, Eleutherodontidae, or the newly erected Euharamiyida (Zheng et al., 2013; Zhou et al., 2013; Bi et al., 2014; Han et al., 2017; Luo et al., 2017; Meng et al., 2017; Mao and Meng, 2019). The taxonomy of the Chinese forms is in flux and is only briefly outlined here (see also Fig. 4). Zhou et al. (2013; see Fig. 4A) described Megaconus and placed it within Mammaliaformes (order Haramiyida, suborder Eleutherodontida, family Eleutherodontidae) but outside of Mammalia. Based on the topology presented by Zhou et al. (2013), Haramiyida includes Thomasia, Haramiyavia, and the eleutherodontid eleutherodontidans Megaconus, Sineleutherus, and Eleutherodon. Zheng et al. (2013; see Fig. 4B) placed their new genus Arboroharamiya in the hierarchy of Mammalia, Allotheria, Haramiyida, and Arboroharamiyidae. Based on the tree topology recovered in Zheng et al. (2013:fig.4), Haramiyida are either paraphyletic, or Multituberculata should be considered a subclade of Haramiyida. Zheng et al. (2013:S13) favored the former interpretation and stated " that 'Haramiyida' should be regarded as a paraphyletic group of those allotherians that are not multituberculates (Butler, 2000).” Similarly, Krause et al. (2014; see Fig. 4C) recovered Allotheria to include the paraphyletic haramiyidans Thomasia and Haramiyavia, Multituberculata, Arboroharamiya, and, in addition to the taxa considered by Zheng et al. (2013), Gondwanatheria.

Bi et al. (2014; see Fig. 4D) erected a new clade, Euharamiyida, of unspecified rank, to accommodate the families Arboroharamiyidae (containing Arboroharamiya), Eleutherodontidae (containing Eleutherodon, Sineleutherus, and Xianshou), and the genera Shenshou (family indet.) and Millsodon (family indet.). In Bi et al.’s (2014) revised diagnosis, Allotheria (which they placed within Mammalia) included Haramiyavia, Thomasia, Allostaffia, Theroteinida (containing the monotypic genus Theroteinus), Euharamiyida (new clade), Multituberculata, and 
Megaconus. Although Bi et al. (2014:582, fig. 4) referred to Allotheria as "Multituberculata and Haramiyida," their tree either rendered Haramiyida paraphyletic or implied that Multituberculata and Euharamiyida should be considered members of Haramiyida. Luo et al. (2015), in their revised description of the mandible and dentition of Haramiyavia, placed Haramiyida, which according to them includes Thomasia, Haramiyavia, Megaconus, and Eleutherodontida (Shenshou, Eleutherodon, Sineleutherus, Arboroharamiya, Xianshou), outside of Mammalia and separate from Multituberculata. Although Megaconus was originally described as an eleutherodontid (Zhou et al., 2013), Luo et al. (2015:fig. 4C; see also Fig. 4E) placed it as sister to Eleutherodontida. This was later reaffirmed by Luo et al. (2017; see Fig. 4F), who resolved Megaconus as sister to Eleutherodonta, but within Euharamiyida.

More recently, Meng et al. (2017) described Maiopatagium and placed it in the order Eleutherodontida, but outside of the family Eleutherodontidae. With the description of Vilevolodon, Luo et al. (2017) recognized Euharamiyida as including Eleutherodonta (rank unspecified, but note different spelling [not Eleutherodontida] from Kermack et al. [1998], Zhou et al. [2013], Luo et al. 2015], and Meng et al. [2017]). Luo et al. (2017) proposed that Eleutherodontidae includes Eleutherodon, Sineleutherus, Arboroharamiya, Xianshou, and Vilevolodon, with Shenshou and Maiopatagium falling outside of Eleutherodontidae but within "the eleutherodontidan clade or eleutherodonts" (Luo et al., 2017:S19). Similar to Luo et al. (2015), Haramiyida was placed outside of Mammalia and separate from Multituberculata in Luo et al. (2017).

Huttenlocker et al. (2018; see Fig. 4G) described the cranium of the Early Cretaceous Cifelliodon and placed it within a descending hierarchy of Mammaliaformes, Haramiyida, family Hahnodontidae. Based on the topology recovered in Huttenlocker et al. (2018:fig. 4), Haramiyida 
are positioned outside of Mammalia, separate from Multituberculata, and include Haramiyavia and Thomasia as sister to Eleutherodontida. In Huttenlocker et al. (2018), Eleutherodontida included Megaconus (although Megaconus had been excluded from Eleutherodontida by Luo et al. [2017]), Vintana, Hahnodontidae, and Eleutherodontidae. In addition to Eleutherodon, Sineleutherus, Arboroharamiya, Xianshou, and Vilevolodon, Huttenlocker et al. (2018) also assigned Millsodon, Maiopatagium, and Shenshou to Eleutherodontidae (although Maiopatagium and Shenshou had been excluded from Eleutherodontidae by Luo et al. [2017]). Lastly, Mao and Meng (2019) assigned two of the paratypes of Shenshou lui to a new genus and species, Qishou jizantang, and to Qishou sp. within the subclass Allotheria, order 'Haramiyida', suborder Euharamiyida, and new family Shenshouidae (along with S. lui). Mao and Meng (2019) did not provide a tree topology but, assuming a similar topology to that of Han et al. (2017) or Wang et al. (2019) (see Fig. 4H), then Haramiyida would either be paraphyletic (as suggested by the quotation marks used by Mao and Meng [2019]) or monophyletic and (as suggested by the suborder rank) include Euharamiyida and therefore also Multituberculata. In sum, the composition and position of Eleutherodonta, Eleutherodontida, Eleutherodontidae, and Haramiyida is unresolved and varies among different authors.

Based on our tree topologies, there is support for a monophyletic Haramiyida (here only comprising the haramiyaviid Haramiyavia and the haramiyid Thomasia), separate from Cifelliodon, Maiopatagium, Vilevolodon, Shenshou, Qishou, Arboroharamiya, and Xianshou (variously referred to as Eleutherodonta, Eleutherodontida, Eleutherodontidae, and Euharamiyida), and also separate from Multituberculata. Whether Haramiyida are placed outside of Mammaliaformes or within Mammalia is ambiguous in our analyses. As such, for communication purposes, here and throughout various chapters in this volume, we restrict the 
term Haramiyida to Thomasia and Haramiyavia, and tentatively still include them in our discussion of Mammaliaformes for the purpose of comparison and until their position is fully resolved and more stable. In addition, we employ the term Euharamiyida to refer to the clade including Arboroharamiya, Maiopatagium, Qishou, Shenshou, Vilevolodon, and Xianshou. In our analysis, we did not include the isolated teeth of the eleutherodontids Eleutherodon, Sineleutherus, and Millsodon. All have been referred to Haramiyida (Kermack et al., 1998; Martin et al., 2010) but have been recovered deeply nested within Euharamiyida by various authors (Bi et al., 2014; Han et al., 2017; Wang et al., 2019; referred to as Eleutherodontida by Luo et al., 2015, 2017; Huttenlocker et al., 2018). If the poorly known eleutherodontids Eleutherodon, Sineleutherus, and Millsodon are confirmed to be members of Euharamiyida, and if a separate position of Haramiyavia and Thomasia outside of Mammaliaformes is maintained in future analyses, then Eleutherodontidae should be removed from Haramiyida and placed within Allotheria.

\section{Other Nodes of Interest}

Eutriconodonta-Eutriconodonta are recovered as monophyletic and sister to Mammalia in all parsimony analyses, as paraphyletic and nested within Mammalia in the undated Bayesian analyses, and as monophyletic but in a polytomy with other mammaliaforms (including Monotremata) in the dated Bayesian analyses. Historically, Eutriconodonta are most commonly recovered as a clade within Mammalia (e.g., Hu et al., 2005; Luo et al., 2007; Zhou et al., 2013; Bi et al., 2014; Krause et al., 2014; Martin et al., 2015; Han et al., 2017; Wang et al., 2019; Zhou et al., 2019). However, exceptions exist; Luo et al. (2017) and Huttenlocker et al. (2018), for example, recovered a paraphyletic Eutriconodonta within Mammalia, and Luo et al. 
(2015) found Eutriconodonta to fall outside of Mammalia. Our data matrix, although broadly encompassing early mammaliaforms, is not intended to resolve relationships of eutriconodontans; it neither extensively samples eutriconodontan taxa, nor includes a range of specific eutriconodontan characters such as, for example, those in Martin et al. (2015). As such, here and in the remainder of this volume, we assume that Eutriconodonta are monophyletic and fall within Mammalia, as in most published studies.

Theria-All of our analyses place Eomaia, Juramaia, Sinodelphys, and Ambolestes outside of Theria. Sampling at the base of Theria is relatively limited in our matrix, as a greater focus was placed on allotherian taxa. A recent analysis by Bi et al. (2018) designed to test relationships at the base of Theria, placed all four taxa (including Sinodelphys, which was originally assigned to Metatheria by Luo et al. [2003]) within Eutheria. Although not without criticism (e.g., Averianov and Lopatin, [2014] questioned the placement of Juramaia within Eutheria, and O'Leary et al. [2013], with a very limited sampling of Cretaceous therians, placed Eomaia outside Theria), most phylogenetic analyses of early mammaliaforms recover Eomaia and Juramaia within Eutheria (e.g., Luo et al., 2011, 2015, 2017; Huttenlocker et al., 2018; King and Beck, 2019; Zhou et al., 2019; Mao et al., 2020). Our matrix is not designed to test relationships of therians and, as such, we refrain from revising these taxa and throughout this memoir refer to Eomaia, Juramaia, Sinodelphys, and Ambolestes as therians or eutherians.

\section{CONCLUSIONS}

In all of our analyses, Adalatherium is placed within Gondwanatheria and is most frequently recovered outside of Sudamericidae and Ferugliotheriidae (with the latter family 
usually found to be a member of the gondwanatherian clade). This is congruent with establishment of the family Adalatheriidae, with the genus Adalatherium as its sole member, as proposed by Krause et al. (2020). The effect of the different coding schemes for the dental formula of Adalatherium has relatively little effect on its phylogenetic position in our analyses. In only two instances did the placements of Adalatherium differ within the same tree inference method (1022_constraint parsimony, 1004_undated Bayesian). Although the tree topologies are largely similar within the same tree inference method, character optimizations and support values for the nodes change between the different coding schemes. Tree inference method has a much greater effect on overall tree topology and placement of Adalatherium than do the different coding schemes for its dental formula.

Gondwanatheria are recovered in all analyses, but whether the ferugliotheriids Ferugliotherium and Trapalcotherium are members of Gondwanatheria is unclear. In the tipdated Bayesian analyses, Ferugliotheriidae are recovered as monophyletic within Multituberculata. Close affinities between the two groups have been proposed before. In particular, the potential presence of a blade-like lower premolar in Ferugliotherium seems to be driving ties between Ferugliotheriidae and Multituberculata. A bladed lower premolar is commonly found in multituberculates but appears to be lacking in other gondwanatherians that can be confidently assessed for this feature.

Gondwanatheria are placed within Allotheria in all of our analyses, either as sister to Multituberculata, sister to Cifelliodon and closely related to Euharamiyida, nested within Multituberculata, or in a polytomy with other allotherians. Some of these proposed relationships appear more plausible than others. The undated Bayesian topology, with Gondwanatheria nested within Multituberculata as sister to Taeniolabidoidea, implies a perplexing paleogeographic 
history and radical character transformations. The implied reacquisition of plesiomorphic mammaliaform features (e.g., presence of a septomaxilla, presence of intranarial process, large lacrimal, large jugal) in the gondwanatherians Vintana and Adalatherium, which are absent in multituberculates, means that we consider the topology recovered in the undated Bayesian analyses unlikely.

The results of the parsimony and tip-dated Bayesian analyses seem more plausible from a paleogeographic and morphological standpoint. Topologies recovered therein suggest an origin of Gondwanatheria by the Middle Jurassic, a time at which Gondwana was still largely intact and which might explain the broad distribution of gondwanatherians across the southern hemisphere. Regardless of the ultimate relationship of Gondwanatheria to either Euharamiyida (tip-dated Bayesian) or Multituberculata (parsimony), our tree topologies suggest a temporally long, unsampled branch (or ghost lineage) leading to Gondwanatheria. This indicates that much of the temporal (and morphological) diversity is yet to be discovered for Gondwanatheria. The currently known distribution of gondwanatherians in South America, Africa, Madagascar, India, and the Antarctic Peninsula can be interpreted either as the result of dispersal from an ancestral portion of Gondwana or vicariance. Given that a mid-Jurassic record for the group is supported by our analyses, it is possible that we are currently sampling endemic products in individual Gondwanan landmasses that were derived from a previously pan-Gondwanan and possibly morphologically more uniform population.

The parsimony topology linking Gondwanatheria and Multituberculata can be seen as the traditional view of gondwanatherian relationships, with Ferugliotheriidae as the basal member of Gondwanatheria that retained a brachydont and relatively generalized molar dentition. In contrast, our tip-dated Bayesian analyses nest ferugliotheriids inside Multituberculata and 
recover a Euharamiyida and Gondwanatheria + Cifelliodon sister-group relationship, which collectively implies that the molar similarities traditionally recognized between Ferugliotheriidae and Sudamericidae (e.g., Krause and Bonaparte, 1993) are homoplastic.

The composition of Allotheria varies in our analyses. In all parsimony and tip-dated Bayesian analyses, Haramiyavia and Thomasia are placed outside of Mammaliaformes, whereas they are recovered in a polytomy with other allotherians in the undated Bayesian analyses. Based on the more frequent placement of Haramiyavia and Thomasia outside of Mammaliaformes, we tentatively conclude that Haramiyavia and Thomasia should be removed from Allotheria, and we consider that Haramiyida should be defined to include only Haramiyavia and Thomasia (possible affiliations with Theroteinus, Allostaffia, Kirtlingtonia, Mojo, and Avashishta still need to be tested in a phylogenetic framework). Unfortunately, other taxa associated with Haramiyida by Butler (2000), including Allostaffia, Eleutherodon, and Theroteinus, as well as the subsequently described Sineleutherus, Millsodon, Kirtlingtonia, Mojo, and Avashishta (Hahn et al., 1987; Butler and Hooker, 2005; Maish et al., 2005; Anantharaman et al., 2006; Martin et al., 2010; Averianov et al., 2011), are only known from isolated teeth. Although dental similarities exist between the eleutherodontids Eleutherodon, Sineleutherus, and Millsodon and the euharamiyidans Shenshou, Qishou, Xianshou, Arboroharamiya, Maiopatagium, and Vilevolodon, the mandibular morphology of the euharamiyidans is distinctly different from at least Haramiyavia, and more similar to those of multituberculates and gondwanatherians. The mandibular morphology for the eleutherodontids Eleutherodon, Sineleutherus, and Millsodon (and, for that matter, any of the purported haramiyidans published before 2013) is unknown and whether it is more similar to those of Haramiyavia or euharamiyidans will likely greatly assist in determining their phylogenetic placement. We tentatively conclude that Allotheria encompasses 
Multituberculata, Gondwanatheria, Euharamiyida, and Hahnodontidae, but more complete specimens are needed to truly assess the relationships among Allostaffia, Eleutherodon, Theroteinus, Thomasia, Sineleutherus, Millsodon, and Kirtlingtonia with Haramiyida or Allotheria.

\section{ACKNOWLEDGMENTS}

For access to comparative material (specimens, casts, 3D prints, or CT data sets), we thank the following curators/colleagues and collections managers: R. Asher, J. Clack, M. Lowe, and R. O’Meara (University Museum of Zoology, Cambridge); S. Bi (Indiana University of Pennsylvania and Yunnan University); P. Brewer and J. Hooker (Natural History Museum, London); Ł. Fostowicz (Polish Academy of Sciences), J. Galkin, J. Meng, and E. Westwig (American Museum of Natural History); A. Huttenlocker (University of Southern California); P. Gill (University of Bristol); C. Jin, H. Wang, and Y. Wang (Institute of Vertebrate Paleontology and Paleoanthropology); T. Lyson (Denver Museum of Nature \& Science); T. Martin (University of Bonn); Q.-J. Meng (Beijing Natural History Museum); Z.-X. Luo (University of Chicago); and C. Zhou (Paleontological Museum of Liaoning). We also extend our sincere gratitude to our colleagues Q.-J. Meng (Beijing Museum of Natural History) and Z.-X. Luo (University of Chicago), who organized the 2018 International Symposium on Mesozoic Mammal Evolution, and made available numerous critically important specimens of Mesozoic mammals, in part through the generosity of the curators and collection managers of many other institutions in China. Finally, we thank E. Panciroli and an anonymous reviewer for their comments on the manuscript. 
For funding, we gratefully acknowledge the National Science Foundation (grants DEB1501497 to SH; DEB-1654949 to JRW; EAR-1122642, EAR-1528273 and EAR-1664432 to DWK) and the Agencia de Promoción Cientifíca y Técnica, Argentina (grant PICT-2016-3682 to GWR).

\section{LITERATURE CITED}

Abdala, F., S. C. Jasinoski, and V. Fernandez. 2013. Ontogeny of the Early Triassic cynodont Thrinaxodon liorhinus (Therapsida): dental morphology and replacement. Journal of Vertebrate Paleontology 33:1408-1431.

Anantharaman, S., G. P. Wilson, D. C. Das Sarma, and W. A. Clemens. 2006. A possible Late Cretaceous 'haramiyidan’ from India. Journal of Vertebrate Paleontology 26:488-490. Averianov, A. O., and A. V. Lopatin. 2014. High-level systematics of placental mammals: current status of the problem. Biology Bulletin 41:801-816.

Averianov, A. O., A. V. Lopatin, and S. A. Krasnolutskii. 2011. The first haramiyid (Mammalia, Allotheria) from the Jurassic of Russia. Doklady Biological Sciences 437:103-106.

Bapst, D. W., A. M. Wright, N. J. Matzke, and G. T. Lloyd. 2016. Topology, divergence dates, and macroevolutionary inferences vary between different tip-dating approaches applied to fossil theropods (Dinosauria). Biology Letters 12:20160237.

Beck, R. M. D. 2017. The skull of Epidolops ameghinoi from the early Eocene Itaboraí fauna, southeastern Brazil, and the affinities of the extinct marsupialiform order Polydolopimorphia. Journal of Mammalian Evolution 24:373-414. 
Beck, R. M. D., and M. S. Y. Lee. 2014. Ancient dates or accelerated rates? Morphological clocks and the antiquity of placental mammals. Proceedings of the Royal Society B: Biological Sciences 281:20141278.

Beck, R. M. D., and M. L. Taglioretti. 2019. A nearly complete juvenile skull of the marsupial Sparassocynus derivatus from the Pliocene of Argentina, the affinities of "sparassocynids", and the diversification of opossums (Marsupialia; Didelphimorphia; Didelphidae). Journal of Mammalian Evolution. doi.org/10.1007/s10914-019-09471-y

Bi, S., Y. Wang, J. Guan, X. Sheng, and J. Meng. 2014. Three new Jurassic euharamiyidan species reinforce early divergence of mammals. Nature 514:579-584.

Bi, S., X. Zheng, X. Wang, N. E. Cignetti, S. Yang, and J. R. Wible. 2018. An Early Cretaceous eutherian and the placental-marsupial dichotomy. Nature 558:390-395.

Bonaparte, J. F. 1986a. Sobre Mesungulatum houssayi y nuevos mamíferos cretácicos de Patagonia, Argentina. Actas IV Congreso Argentino de Paleontología y Bioestratigrafía $2: 48-61$.

Bonaparte, J. F. 1986b. A new and unusual Late Cretaceous mammal from Patagonia. Journal of Vertebrate Paleontology 6:264-270.

Bonaparte, J. F. 1986c. History of the terrestrial Cretaceous vertebrates of Gondwana. Actas IV Congreso Argentino de Paleontología y Bioestratigrafía 2:63-95.

Bonaparte, J. F. 1987. The Late Cretaceous fauna of Los Alamitos, Patagonia, Argentina. Part VIII- the mammals. Revista del Museo Argentino de Ciencias Naturales "Bernardino Rivadavia," Paleontología 3:163-169.

Bonaparte, J. F. 1988. Specialized dentitions in two Cretaceous mammals from Patagonia; pp. 207-215 in D. E. Russell, J.-P. Santoro, and D. Sigogneau-Russell (eds.), Teeth 
Revisited: Proceedings of the VII ${ }^{\text {th }}$ International Symposium on Dental Morphology, Paris 1986. Mémoires du Muséum National d'Histoire Naturelle, Paris, série C, 53.

Bonaparte, J. F. 1990. New Late Cretaceous mammals from the Los Alamitos Formation, northern Patagonia. National Geographic Research 6:63-93.

Bonaparte, J. F. 2017. Notas sobre el origen de los gliptodontes. Reunión de Comunicaciones de la Asociación Paleontológica Argentina, San Luis, 2017, Program.

Bonaparte, J. F., and R. Pascual. 1987. Los mamíferos (Eotheria, Allotheria y Theria) de la Formación Los Alamitos, Campaniano de Patagonia, Argentina. Memorias IV Congreso Latinoamericano de Paleontologia, Bolivia 1:361-378.

Bonaparte, J. F., L. Van Valen, and A. Kramartz. 1993. La fauna local de Punta Peligro, Paleoceno Inferior, de la Provincia del Chubut, Patagonia, Argentina. Evolutionary Monographs 14:1-61.

Bouckaert R., T. G. Vaughan, J. Barido-Sottani, S. Duchêne, M. Fourment, A. Gavryushkina, J. Heled, G. Jones, D. Kühnert, N. De Maio, M. Matschiner, F. K. Mendes, N. F. Müller, H. A. Ogilvie, L. du Plessis, A. Popinga, A. Rambaut, D. Rasmussen, I. Siveroni, M. A. Suchard, C.-H. Wu, D. Xie, C. Zhang, T. Stadler, and A. J. Drummond. 2019. BEAST 2.5: An advanced software platform for Bayesian evolutionary analysis. PLoS Computational Biology 15:e1006650.

Bremer, K. 1994. Branch support and tree stability. Cladistics 10:295-304.

Broom, R. 1914. On the structure and affinities of the Multituberculata. Bulletin of the American Museum of Natural History 33:115-134.

Butler, P. M. 2000. Review of the early allotherian mammals. Acta Palaeontologica Polonica 45:317-342. 
Butler, P. M., and J. J. Hooker. 2005. New teeth of allotherian mammals from the English Bathonian, including the earliest multituberculates. Acta Palaeontologica Polonica 50:185-207.

Butler, P. M., and G. T. MacIntyre. 1994. Review of the British Haramiyidae (?Mammalia, Allotheria), their molar occlusion and relationships. Philosophical Transactions of the Royal Society of London B 345:433-458.

Chimento, N. R., F. L. Agnolin, and F. E. Novas. 2014. The bizarre 'metatherians' Groeberia and Patagonia, late surviving members of gondwanatherian mammals. Historical Biology 27:603-623.

Cifelli, R. L., and B. M. Davis. 2013. Palaeontology: Jurassic fossils and mammalian antiquity. Nature 500:160-161.

Clemens, W. A., and Z. Kielan-Jaworowska. 1979. Multituberculata; pp. 99-149 in J. A. Lillegraven, Z. Kielan-Jaworowska, and W. A. Clemens (eds.), Mesozoic Mammals, the First Two-thirds of Mammalian History. University of California Press, Berkeley, California.

Close, R. A., M. Friedman, G. T. Lloyd, and R. B. Benson. 2015. Evidence for a mid-Jurassic adaptive radiation in mammals. Current Biology 25:2137-2142.

Cope, E. D. 1884. The Tertiary Marsupialia. American Naturalist 18:686-697.

Crompton, A. W. 1963. Tooth replacement in the cynodont Thrinaxodon liorhinus Seeley. Annals of the South African Museum 46:479-521.

Crompton, A. W., and F. A. Jenkins, Jr. 1979. Origin of mammals; pp. 59-73 in J. A. Lillegraven, Z. Kielan-Jaworowska, and W. A. Clemens (eds.), Mesozoic Mammals: The 
First Two-thirds of Mammalian History. University of California Press, Berkeley, California.

Csiki-Sava, Z., M. Vremir, J. Meng, S. L. Brusatte, and M. A. Norell. 2018. Dome-headed, small-brained island mammal from the Late Cretaceous of Romania. Proceedings of the National Academy of Sciences of the United States of America 115:4857-4862.

Goin, F. J., M. F. Tejedor, L. Chornogubsky, G. M. López, J. N. Gelfo, M. Bond, M. O. Woodburne, Y. Gurovich, and M. Reguero. 2012. Persistence of a Mesozoic, non-therian mammalian lineage (Gondwanatheria) in the mid-Paleogene of Patagonia. Naturwissenschaften 99:449-463.

Goloboff, P. A., J. Farris, and K. Nixon. 2008. TNT: a free program for phylogenetic analysis. Cladistics 24:774-786.

Gow, C. E. 1980. The dentitions of the Tritheledontidae (Therapsida: Cynodontia). Proceedings of the Royal Society of London B 208:461-481.

Gow, C. E. 1985. Dentitions of juvenile Thrinaxodon (Reptilia: Cynodontia) and the origin of mammalian diphyodonty. Annals of the Geological Survey of South Africa 19:1-17.

Gurovich, Y. 2006. Bio-evolutionary aspects of Mesozoic mammals: description, phylogenetic relationships and evolution of the Gondwanatheria (Late Cretaceous and Paleocene of Gondwana). Ph.D. dissertation, Universidad Nacional de Buenos Aires, Buenos Aires, Argentina, $621 \mathrm{pp}$.

Gurovich, Y., and R. Beck. 2009. The phylogenetic affinities of the enigmatic mammalian clade Gondwanatheria. Journal of Mammalian Evolution 16:25-49.

Hahn, G. 1973. Neue Zähne von Haramiyiden aus der deutschen Ober-Trias und ihre Beziehungen zu den Multituberculaten. Palaeontographica Abteilung A 142:1-15. 
Hahn, G., and R. Hahn. 2006. Fossilium Catalogus I: Animalia, Catalogus Plagiaulacidorum cum figuris (Multituberculata superjurassica et subcretacea). Backhuys Publishers, Leiden, Netherlands, 348 pp.

Hahn, G., J.-C. Lepage, and G. Wouters. 1987. Ein Multituberculaten-Zahn aus der Ober-Trias von Gaume (S-Belgien). Bulletin de la Société belge de Géologie 96:39-47.

Hahn, G., D. Sigogneau-Russell, and G. Wouters. 1989. New data on Theroteinidae: their relations with Paulchoffatiidae and Haramiyidae. Geologica et Paleontologica 23:205215.

Han, G., F. Mao, S. Bi, Y. Wang, and J. Meng. 2017. A Jurassic gliding euharamiyidan mammal with an ear of five auditory bones. Nature 551:451-456.

Harrison, L. B., and H. C. E. Larsson. 2015. Among-character rate variation distributions in phylogenetic analysis of discrete morphological characters. Systematic Biology 64:307324.

Heinrich, W. D. 1999. First haramiyid (Mammalia, Allotheria) from the Mesozoic of Gondwana. Fossil Record 2:159-170.

Heinrich, W. D. 2001. New records of Staffia aenigmatica (Mammalia, Allotheria, Haramiyida) from the Upper Jurassic of Tendaguru in southeastern Tanzania, East Africa. Fossil Record 4:239-255.

Heinrich, W. D. 2004. Allostaffia, a new genus name for Staffia Heinrich, 1999 (Allotheria, Haramiyida) preoccupied by Staffia Schubert, 1911 (Protista, Foraminifera). Mitteilungen aus dem Museum für Naturkunde in Berlin, Geowissenschaftliche Reihe 7:153.

Hoffmann, S. 2016. Late Cretaceous mammals from Madagascar and their implications for the systematics of Mesozoic Mammaliaformes. Ph.D. dissertation, Stony Brook University, 
Stony Brook, New York, 532 pp.

Hoffmann, S., and E. C. Kirk. 2020. Inner ear morphology of Adalatherium hui (Mammalia, Allotheria) from the Late Cretaceous of Madagascar; pp. $\mathrm{xx}-\mathrm{xx}$ in D. W. Krause and S. Hoffmann (eds.), Adalatherium hui (Mammalia, Gondwanatheria) from the Late Cretaceous of Madagascar. Society of Vertebrate Paleontology Memoir XX. Journal of Vertebrate Paleontology XX(X, Supplement).

Hopson, J. A., and J. W. Kitching. 2001. A probainognathian cynodont from South Africa and the phylogeny of nonmammalian cynodonts. Bulletin of the Museum of Comparative Zoology 156:5-35.

Hu, Y. 2006. Postcranial morphology of Repenomamus (Eutriconodonta, Mammalia): implications for the higher-level phylogeny of mammals. Ph. D. dissertation, City University of New York, New York, New York, 405 pp.

Hu, Y., J. Meng, Y. Wang, and C.-K. Li. 2005. Large Mesozoic mammals fed on young dinosaurs. Nature 433:149-152.

Huttenlocker, A. K., D. M. Grossnickle, J. L. Kirkland, J. A. Schultz, and Z.-X. Luo. 2018. Latesurviving stem mammal links the lowermost Cretaceous of North America and Gondwana. Nature 558:108-112.

Jenkins, F. A., Jr., S. M. Gatesy, N. H. Shubin, and W. W. Amaral. 1997. Haramiyids and Triassic mammalian evolution. Nature 385:715-718.

Kermack, K. A., D. M. Kermack, P. M. Lees, and J. R. E. Mills. 1998. New multituberculate-like teeth from the Middle Jurassic of England. Acta Palaeontologica Polonica 43:581-606.

Kielan-Jaworowska, Z., and J. F. Bonaparte. 1996. Partial dentary of a multituberculate mammal from the Late Cretaceous of Argentina and its taxonomic implications. Museo Argentino 
de Ciencias Naturales "Bernardino Rivadavia" e Instituto Nacional de Investigación de las Ciencias Naturales 145:1-9.

Kielan-Jaworowska, Z., and J. H. Hurum. 1997. Djadochtatheria-a new suborder of multituberculate mammals. Acta Palaeontologica Polonica 42:201-242.

Kielan-Jaworowska, Z., and J. H. Hurum. 2001. Phylogeny and systematics of multituberculate mammals. Palaeontology 44:389-429.

Kielan-Jaworowska, Z., R. L. Cifelli, and Z.-X. Luo. 2004. Mammals from the Age of Dinosaurs: Origins, Evolution, and Structure. Columbia University Press, New York, New York, $630 \mathrm{pp}$.

Kielan-Jaworowska, Z., E. Ortiz-Jaureguizar, C. Vieytes, R. Pascual, and F. J. Goin. 2007. First ?cimolodontan multituberculate mammal from South America. Acta Palaeontologica Polonica 52:257-262.

King, B., and R. M. D. Beck. 2019. Bayesian tip-dated phylogenetics: topological effects, stratigraphic fit and the early evolution of mammals. BioRxiv:533885.

Krause, D. W. 1993. Vucetichia (Gondwanatheria) is a junior synonym of Ferugliotherium (Multituberculata). Journal of Paleontology 67:321-324.

Krause, D. W., and J. F. Bonaparte. 1993. Superfamily Gondwanatherioidea: a previously unrecognized radiation of multituberculate mammals in South America. Proceedings of the National Academy of Sciences of the United States of America 90:9379-9383.

Krause, D. W., and S. Hoffmann (eds.). 2020. Adalatherium hui (Mammalia, Gondwanatheria) from the Late Cretaceous of Madagascar. Society of Vertebrate Paleontology Memoir XX. Journal of Paleontology XX(X, Supplement). 
Krause, D. W., Z. Kielan-Jaworowska, and J. F. Bonaparte. 1992. Ferugliotherium Bonaparte, the first known multituberculate from South America. Journal of Vertebrate Paleontology $12: 351-376$.

Krause, D. W., J. R. Groenke, S. Hoffmann, R. R. Rogers, and L. J. Rahantarisoa. 2020. Introduction to Adalatherium hui, a complete and well-preserved gondwanatherian mammal from the Late Cretaceous of Madagascar; pp. $\mathrm{xx}-\mathrm{xx}$ in D. W. Krause and S. Hoffmann (eds.), Adalatherium hui (Mammalia, Gondwanatheria) from the Late Cretaceous of Madagascar. Society of Vertebrate Paleontology Memoir XX. Journal of Paleontology XX(X, Supplement).

Krause, D. W., G. V. R. Prasad, W. von Koenigswald, A, Sahni, and F. E. Grine. 1997. Cosmopolitanism among Late Cretaceous Gondwanan mammals. Nature 390:504-507.

Krause, D. W., S. Hoffmann, Y. Hu, J. B. Rossie, J. R. Wible, G. W. Rougier, and J. R. Groenke. 2020. Craniofacial morphology of Adalatherium hui (Mammalia, Allotheria) from the Late Cretaceous of Madagascar; pp. Xx-xx in D. W. Krause and S. Hoffmann (eds.), Adalatherium hui (Mammalia, Gondwanatheria) from the Late Cretaceous of Madagascar. Society of Vertebrate Paleontology Memoir XX. Journal of Vertebrate Paleontology XX(X, Supplement).

Krause, D. W., Y. Hu, S. Hoffmann, J. R. Groenke, J. A. Schultz, A. R. Evans, W. v. Koenigswald, and G. W. Rougier. 2020. Dental morphology of Adalatherium hui (Mammalia, Gondwanatheria) from the Late Cretaceous of Madagascar; pp. $x x-x x$ in D. W. Krause and S. Hoffmann (eds.), Adalatherium hui (Mammalia, Gondwanatheria) from the Late Cretaceous of Madagascar. Society of Vertebrate Paleontology Memoir XX. Journal of Paleontology XX(X, Supplement). 
Krause, D. W., S. Hoffmann, Y. Hu, J. R. Wible, G. W. Rougier, E. C. Kirk, J. R. Groenke, R. R. Rogers, J. B. Rossie, J. A. Schultz, A. R. Evans, W. v. Koenigswald, and L. J. Rahantarisoa. 2020. Skeleton of Cretaceous gondwanatherian mammal from Madagascar reflects long-term insularity. Nature XXX:XXX-XXx.

Krause, D. W., S. Hoffmann, J. R. Wible, E. C. Kirk, J. A. Schultz, W. v. Koenigswald, J. R. Groenke, J. B. Rossie, P. M. O’Connor, E. R. Seiffert, E. R. Dumont, W. L. Holloway, R. R. Rogers, L. J. Rahantarisoa, A. D. Kemp, and H. Andriamialison. 2014. First cranial remains of gondwanatherian mammal reveal remarkable mosaicism. Nature 515:512_ 517.

Lee, M. S. Y., and A. M. Yates. 2018. Tip-dating and homoplasy: reconciling the shallow molecular divergences of modern gharials with their long fossil record. Proceedings of the Royal Society B: Biological Sciences 285:20181071.

Lee, M. S. Y., A. Cau, D. Naish, and G. J. Dyke. 2014. Morphological clocks in paleontology, and a mid-Cretaceous origin of crown Aves. Systematic Biology 63:442-449.

Lewis, P. O. 2001. A likelihood approach to estimating phylogeny from discrete morphological character data. Systematic Biology 50:913-925.

Lillegraven, J. A., Z. Kielan-Jaworowska, and W. A. Clemens (eds.). 1979. Mesozoic Mammals: The First Two Thirds of Mammalian History. University of California Press, Berkeley, California, $311 \mathrm{pp}$.

Liu, J., and P. Olsen. 2010. The phylogenetic relationships of Eucynodontia (Amniota: Synapsida). Journal of Mammalian Evolution 17:151-176.

Luckett, W. P. 1993. An ontogenetic assessment of dental homologies in therian mammals; pp. 182-204 in F. S. Szalay, M. J. Novacek, and M. C. McKenna (eds.), Mammal Phylogeny: 
Mesozoic Differentiation, Multituberculates, Monotremes, Early Therians, and Marsupials. Springer-Verlag, New York, New York.

Luo, Z.-X., Z. Kielan-Jaworowska, and R. L. Cifelli. 2002. In quest for a phylogeny of Mesozoic mammals. Acta Palaeontologica Polonica 47:1-78.

Luo, Z.-X., Z. Kielan-Jaworowska, and R. L. Cifelli. 2004. Evolution of dental replacement in mammals. Bulletin of the Carnegie Museum of Natural History 36:159-175.

Luo, Z.-X., P. Chen, G . Li, and M. Chen. 2007. A new eutriconodont mammal and evolutionary development in early mammals. Nature 446:288-293.

Luo, Z.-X., Q. Ji, J. R. Wible, and C.-X. Yuan. 2003. An Early Cretaceous tribosphenic mammal and metatherian evolution. Science 302:1934-1939.

Luo, Z.-X., C.-X. Yuan, Q.-J. Meng, and Q. Ji. 2011. A Jurassic eutherian mammal and divergence of marsupials and placentals. Nature 476:442-445.

Luo, Z.-X., S. M. Gatesy, F. A. Jenkins, Jr., W. W. Amaral, and N. H. Shubin. 2015. Mandibular and dental characteristics of Late Triassic mammaliaform Haramiyavia and their ramifications for basal mammal evolution. Proceedings of the National Academy of Sciences of the United States of America 112:E7101-E7109.

Luo, Z.-X., Q.-J. Meng, D. M. Grossnickle, D. Liu, A. I. Neander, Y.-G. Zhang, and Q. Ji. 2017. New evidence for mammaliaform ear evolution and feeding adaptation in a Jurassic ecosystem. Nature 548:326-329.

Maddison, W. P., and D. R. Maddison. 2019. Mesquite: a modular system for evolutionary analysis. Version $3.61 \mathrm{http}: / / w w w . m e s q u i t e p r o j e c t . o r g$

Maisch, M. W., A. T. Matzke, F. Grossmann, H. Stöhr, H.-U. Pfretzschner, and G. Sun. 2005. The first haramiyoid mammal from Asia. Naturwissenschaften 92:40-44. 
Mao, F.-Y., and J. Meng. 2019. A new haramiyidan mammal from the Jurassic Yanliao Biota and comparisons with other haramiyidans. Zoological Journal of the Linnean Society 186:529-552.

Mao, F.-Y., Y.-Q. Wang, and J. Meng. 2016. New specimens of the multituberculate mammal Sphenopsalis from China: implications for phylogeny and biology of taeniolabidoids. Acta Palaeontologica Polonica 61:429-454.

Mao, F.-Y., X.-T. Ting, X.-L. Wang, Y.-Q. Wang, S.-D. Bi, and J. Meng. 2019. Evidence of diphyodonty and heterochrony for dental development in euharamiyidan mammals from Jurassic Yanliao Biota. Vertebrata PalAsiatica 57:51-76.

Mao, F.-Y., Y. Hu, C. Li, Y. Wang, M. H. Chase, A. K. Smith, and J. Meng. 2020. Integrated hearing and chewing modules decoupled in a Cretaceous stem therian mammal. Science 367:305-308.

Marsh, O. C. 1880. Notice on Jurassic mammals representing two new orders. American Journal of Science 3:235-239.

Martin, T., A. O. Averianov, and H.-U. Pfretzschner. 2010. Mammals from the Late Jurassic Qigu Formation in the southern Junggar Basin, Xinjiang, northwest China. Palaeobiodiversity and Palaeoenvironments 90:295-319.

Martin, T., J. Marugán-Lobón, R. Vullo, H. Martín-Abad, Z.-X. Luo, and A. D. Buscalioni. 2015. A Cretaceous eutriconodont and integument evolution in early mammals. Nature 526:380-384.

Martinelli, A. G., and J. F. Bonaparte. 2011. Postcanine replacement in Brasilodon and Brasilitherium (Cynodontia, Probainognathia) and its bearing in cynodont evolution; pp. 179-186 in J. Calvo, J. Porfiri, B. Gonzales Riga, and D. Dos Santos (eds.), 
Paleontologia y Dinosaurios desde América Latina. Editora de la Universidad de Cuyo, Mendoza, Argentina.

Matzke, N. J., and A. Wright. 2016. Inferring node dates from tip dates in fossil Canidae: the importance of tree priors. Biological Letters 12:20160328.

Meng, J., S. Bi, Y. Wang, X. Zheng, and X. Wang. 2014. Dental and mandibular morphologies of Arboroharamiya (Haramiyida, Mammalia): a comparison with other haramiyidans and Megaconus and implications for mammalian evolution. PLoS ONE 9:e113847.

Meng, Q.-J., D. M. Grossnickle, D. Liu, Y.-G. Zhang, A. I. Neander, Q. Ji, and Z.-X. Luo. 2017. New gliding mammaliaforms from the Jurassic. Nature 548:291-296.

Miller, M. A., W. Pfeiffer, and T. Schwartz. 2010. Creating the CIPRES Science Gateway for inference of large phylogenetic trees. Proceedings of the Gateway Computing Environments (GCE) Workshop, New Orleans:1-8.

Mones, A. 1987. Gondwanatheria, un nuevo orden de Mamíferos Sudamericano (Mammalia: Edentata: ?Xenarthra). Comunicaciones Paleontológicas del Museo de Historia Natural de Montevideo 18:237-240.

O’Connor, P., D. W. Krause, N. J. Stevens, J. R. Groenke, R. D. E. MacPhee, D. C. Kalthoff, and E. M. Roberts. 2019. A new mammal from the Turonian-Campanian (Upper Cretaceous) Galula Formation, southwestern Tanzania. Acta Palaeontologica Polonica 64:65-84.

O'Leary, M. A., J. I. Bloch, J. J. Flynn, T. J. Gaudin, A. Giallombardo, N. P. Giannini, S. L. Goldberg, B. P. Kraatz, Z.-X. Luo, J. Meng, X. J. Ni, M. J. Novacek, F. A. Perini, Z. S. Randall, G. W. Rougier, E. J. Sargis, M. T. Silcox, N. B. Simmons, M. Spaulding, P. M. Velazco, M. Weksler, J. R. Wible, and A. L. Cirranello. 2013. The placental mammal 
ancestor and the post-K-Pg radiation of placentals. Science 339:662-667.

Pascual, R., and E. Ortiz-Jaureguizar. 2007. The Gondwanan and South American episodes: two major and unrelated moments in the history of the South American mammals. Journal of Mammalian Evolution 14:75-137.

Pascual, R., F. J. Goin, D. W. Krause, E. Ortiz-Jaureguizar, and A. A. Carlini. 1999. The first gnathic remains of Sudamerica: implications for gondwanathere relationships. Journal of Vertebrate Paleontology 19:373-382.

Prasad, G. V. R., O. Verma, A. Sahni, D. W. Krause, A. Khosla, and V. Parmar. 2007. A new Late Cretaceous gondwanatherian mammal from central India. Proceedings of the Indian National Science Academy 73:17-24.

Rambaut, A., M. A. Suchard, D. Xie, and A. J. Drummond. 2014. Tracer v1.6. Available from http://beast.bio.ed.ac.uk/Tracer.

Ronquist, F., M. Teslenko, P. van der Mark, D. L. Ayres, A. Darling, S. Hohna, B. Larget, L. Liu, M. A. Suchard, and J. P. Huelsenbeck. 2012. MrBayes 3.2: efficient Bayesian phylogenetic inference and model choice across a large model space. Systematic Biology 61:539-542.

Rougier, G. W., S. Apesteguía, and L. C. Gaetano. 2011. Highly specialized mammalian skulls from the Late Cretaceous of South America. Nature 479:98-102.

Rougier, G. W., M. J. Novacek, and D. Dashzeveg. 1997. A new multituberculate from the Late Cretaceous locality Ukhaa Tolgod, Mongolia: considerations on multituberculate interrelationships. American Museum Novitates 3191:1-28.

Rougier, G. W., J. R. Wible, and M. J. Novacek. 1998. Implications of Deltatheridium specimens for early marsupial history. Nature 396:459-463. 
Rougier, G. W., A. G. Martinelli, A. M. Forasiepi, and M. J. Novacek. 2007. New Jurassic mammals from Patagonia, Argentina: a reappraisal of australosphenidan morphology and interrelationships. American Museum Novitates 3566:1-54.

Rougier, G. W., L. Chornugubsky, S. Casadio, N. P. Arango, and A. Giallombardo. 2009. Mammals from the Allen Formation, Late Cretaceous, Argentina. Cretaceous Research $30: 223-238$.

Rougier, G. W., A. S. Sheth, B. K. Spurlin, M. Bolortsetseg, and M. J. Novacek. 2016. Craniodental anatomy of a new Late Cretaceous multituberculate mammal from Udan Sayr, Mongolia. Acta Paleontologica Polonica 67:197-248.

Rougier, G. W., L. Gaetano, B. R. Drury, R. Colella, R. O. Gomez, and N. P. Arango. 2011. A review of the Mesozoic mammalian record of South America; pp. 195-214 in J. Calvo, J. Porfiri, B. G. Riga, and D. Dos Santos (eds.), Palaeontología y dinosaurios desde América Latina. Editorial de la Universidad Nacional de Cuyo, Mendoza, Argentina. Rowe, T. B. 1987. Definition and diagnosis in the phylogenetic system. Systematic Zoology 36:208-2011.

Rowe, T. B. 1988. Definition, diagnosis, and origin of Mammalia. Journal of Vertebrate Paleontology 8:241-264.

Scillato-Yané, G. J., and R. Pascual. 1984. Un peculiar Paratheria, Edentata (Mammalia) del Paleoceno de Patagonia. Primeras Jornadas Argentinas de Paleontología de Vertebrados, Resúmenes: 15.

Scillato-Yané, G. J., and R. Pascual. 1985. Un peculiar Xenarthra del Paleoceno medio de Patagonia (Argentina). Su importancia en la sistemática de los Paratheria. Ameghiniana $21: 173-176$. 
Seeley, H. G. 1894. I. Researches on the structure, organization, and classification of the fossil Reptilia.-Part IX., Section 2. The reputed mammals from the Karroo Formation of Cape Colony. Philosophical Transactions of the Royal Society of London B 185:1019-1028. Sereno, P. C. 2006. Shoulder girdle and forelimb in multituberculates: evolution of parasagittal forelimb posture in mammals; pp. 315-366 in M. T. Carrano, T. J. Gaudin, R. W. Blob, and J. R. Wible (eds.), Amniote Paleobiology: Perspectives on the Evolution of Mammals, Birds, and Reptiles. University of Chicago Press, Chicago, Illinois.

Sigogneau-Russell, D., P. Frank, and J. Hemmerlé. 1986. A new family of mammals from the lower part of the French Rhaetic; pp. 99-108 in K. Padian (ed.), The Beginning of the Age of Dinosaurs: Faunal Change across the Triassic-Jurassic Boundary. Cambridge University Press, Cambridge, U.K.

Simmons, N. B. 1993. Phylogeny of Multituberculata; pp. 146-164 in F. S. Szalay, M. J. Novacek, and M. C. McKenna (eds.), Mammal Phylogeny: Mesozoic Differentiation, Multituberculates, Monotremes, Early Therians, and Marsupials. Springer-Verlag, New York, New York.

Simpson, G. G. 1928. A Catalogue of the Mesozoic Mammalia in the Geological Department of the British Museum. Trustees of the British Museum, London, U.K., 125 pp.

Simpson, G. G. 1929. American Mesozoic Mammalia. Memoirs of the Paebody Museum of Yale University 3:1-264.

Simpson, G. G. 1945. The principles of classification and a classification of mammals. Bulletin of the American Museum of Natural History 85:1-350.

Smith, T., and V. Codrea. 2015. Red iron-pigmented tooth enamel in a multituberculate mammal from the Late Cretaceous Transylvanian “Hațeg Island.” PLoS ONE 10:e0132550. 
Sterli, J., M. S. de la Fuente, and G. W. Rougier. 2018. New remains of Condorchelys antiqua (Testudinata) from the Early-Middle Jurassic of Patagonia: anatomy, phylogeny, and paedomorphosis in the early evolution of turtles. Journal of Vertebrate Paleontology $38: 1-17$.

Swofford, D. L. 2003. PAUP*. Phylogenetic Analysis Using Parsimony (*and Other Methods). Version 4. Sinauer Associates, Sunderland, Massachusetts.

Turner, A. H., A. C. Pritchard, and N. J. Matzke. 2017. Empirical and Bayesian approaches to fossil-only divergence times: a study across three reptile clades. PloS ONE 12:e0169885.

Wang, H., J. Meng, and Y. Wang. 2019. Cretaceous fossil reveals a new pattern in mammalian middle ear evolution. Nature 576:102-105.

Watson, D. M. S. 1942. On Permian and Triassic tetrapods. Geological Magazine 79:81-116.

Wible, J. R., S. L. Shelley, and S. Bi. 2019. New genus and species of djadochtatheriid multituberculate (Allotheria, Mammalia) from the Upper Cretaceous Bayan Mandahu Formation of Inner Mongolia. Annals of Carnegie Museum 85:285-327.

Wible, J. R., G. W. Rougier, M. J. Novacek, and R. J. Asher. 2009. The eutherian mammal Maelestes gobiensis from the Late Cretaceous of Mongolia and the phylogeny of Cretaceous Eutheria. Bulletin of the American Museum of Natural History 327:1-123.

Wilson, G. P., D. C. Das Sarma, and S. Anantharaman. 2007. Late Cretaceous sudamericid gondwanatherians from India with paleobiogeographic considerations of Gondwanan mammals. Journal of Vertebrate Paleontology 27:521-531.

Xu, L., X. Zhang, H. Pu, S. Jia, J. Zhang, J. Lü, and J. Meng. 2015. Largest known Mesozoic multituberculate from Eurasia and implications for multituberculate evolution and biology. Scientific Reports 5:14950. 
Yuan, C.-X., Q. Ji, Q. J. Meng, A. R. Tabrum, and Z.-X. Luo. 2013. Earliest evolution of multituberculate mammals revealed by a new Jurassic fossil. Science 341:779-783.

Zheng, X., S. Bi, X. Wang, and J. Meng. 2013. A new arboreal haramiyid shows the diversity of crown mammals in the Jurassic period. Nature 500:199-202.

Zhou, C.-F., S. Wu, T. Martin, and Z.-X. Luo. 2013. A Jurassic mammaliaform and the earliest mammalian evolutionary adaptations. Nature 500:163-167.

Zhou, C.-F., B.-A. S. Bhullar, A. I. Neander, T. Martin, and Z.-X. Luo. 2019. New Jurassic mammaliaform sheds light on early evolution of mammal-like hyoid bones. Science 365:276-279.

Ziegler, A. C. 1971. A theory of the evolution of therian dental formulas and replacement patterns. The Quarterly Review of Biology 46:226-249.

Zimicz, A. N., and F. J. Goin. 2020. A reassessment of the genus Groeberia Patterson, 1952 (Mammalia, Metatheria): functional and phylogenetic implications. Journal of Systematic Palaeontology. doi.org/10.1080/14772019.2019.170619. 


\section{FIGURE CAPTIONS}

FIGURE 1. Simplified tree topology of strict consensus trees for parsimony analyses using three different coding schemes for Adalatherium based on lower dental formulae $(1013,1022,1004)$ with nodes within multituberculates either unconstrained $(\mathbf{A}, \mathbf{B})$ or constrained $(\mathbf{C}, \mathbf{D})$. A, simplified strict consensus tree of 16 most parsimonious trees (MPTs) from unconstrained analysis using coding scheme 1013 (tree topology but not Bremer support identical to 1022); B, simplified strict consensus tree of eight MPTs from unconstrained analysis using coding scheme 1004; C, simplified strict consensus tree of 16 MPTs from constrained analysis using coding scheme 1013 (tree topology but not Bremer support identical to 1004_constraint); D, simplified strict consensus tree of 40 MPTs from constrained analysis using coding scheme 1022. Bremer values for selected nodes indicated next to node. Adalatherium highlighted in yellow, gondwanatherians in green shades (ferugliotheriids in dark green, Galulatherium in teal, sudamericids in light green), multituberculates in light blue, euharamiyidans in dark blue, haramiyidans in purple. [planned for page width, color]

FIGURE 2. Simplified tree topology of 'halfcompat' (50\% majority rule) trees for undated Bayesian analyses using three different coding schemes for Adalatherium based on lower dental formulae (1013, 1022, 1004). A, simplified halfcompat tree of 1013_undated; B, simplified halfcompat tree of 1022_undated; and C, simplified halfcompat tree of 1004_undated. Posterior probabilities for selected nodes indicated next to node. Adalatherium highlighted in yellow, gondwanatherians in green shades (ferugliotheriids - dark, Galulatherium - medium, sudamericids - light), multituberculates in light blue, euharamiyidans in dark blue, haramiyidans 
in purple. [planned for page width, color]

FIGURE 3. Simplified tree topology of 'halfcompat' (50\% majority rule) trees for tip-dated Bayesian analyses using three different coding schemes for Adalatherium based on lower dental formulae $(1013,1022,1004)$. A, simplified halfcompat tree of 1013 dated; B, simplified halfcompat tree of 1022_dated; and C, simplified halfcompat tree of 1004_dated. Posterior probabilities for selected nodes indicated next to node. Adalatherium highlighted in yellow, gondwanatherians in green shades (ferugliotheriids in dark green, Galulatherium in teal, sudamericids in light green), multituberculates in light blue, euharamiyidans in dark blue, haramiyidans in purple. [planned for page width, color]

FIGURE 4. Simplified tree topology of mammaliaform relationships based on A, Zhou et al. (2013); B, Zheng et al. (2013); C, Krause et al. (2014); D, Bi et al. (2014); E, Luo et al. (2015); F, Luo et al. (2017); G, Huttenlocker et al. (2018); and H, Han et al. (2017). Millsodon, Allostaffia, Theroteinida were not included in the analysis of Bi et al. (2014:Supplementary Information), but the authors assigned Millsodon to Euharamiyida, and Allostaffia and Theroteinida to Allotheria. Megaconus was included in one of three analyses by Bi et al. (2014:Supplementary Information) and was assigned to Allotheria, contrary to its placement in their analyses. These taxa are not included in part D. Eutriconodonta are not monophyletic in $\mathbf{F}$ and $\mathbf{G}$ and are therefore labeled as 'eutriconodonts.' [planned for page width, grayscale] 
TABLE 1. Metrics of six parsimony analyses of systematic position of Adalatherium.

\begin{tabular}{|c|c|c|c|c|}
\hline \multicolumn{5}{|c|}{ Parsimony } \\
\hline & TL & MPT & CI & RI \\
\hline 1004 & 2306 & 8 & 0.3027 & 0.7017 \\
\hline 1004_const & 2316 & 16 & 0.3014 & 0.6999 \\
\hline 1013 & 2315 & 16 & 0.3015 & 0.7001 \\
\hline 1013_const & 2321 & 16 & 0.3007 & 0.6990 \\
\hline 1022 & 2316 & 16 & 0.3014 & 0.7000 \\
\hline 1022_const & 2403 & 40 & 0.2905 & 0.6839 \\
\hline
\end{tabular}

TL, Tree Length; MPT, number of most parsimonious trees; CI, consistency index; RI, retention index. 
TABLE 2. List of unambiguous synapomorphies for Adalatherium, Gondwanatheria, and Multituberculata + Gondwanatheria, for six parsimony analyses.

\begin{tabular}{lccccc}
\hline \multicolumn{5}{c}{ Adalatherium } \\
\hline $\mathbf{1 0 1 3}$ & $\mathbf{1 0 1 3 c o n s}$ & $\mathbf{1 0 2 2}$ & $\mathbf{1 0 2 2 c o n s}$ & $\mathbf{1 0 0 4}$ & $\mathbf{1 0 0 4 c o n s}$ \\
$122 / 0$ & $337 / 0$ & $122 / 0$ & $337 / 0$ & $122 / 0$ & $337 / 0$ \\
$131 / 1$ & $338 / 1$ & $131 / 1$ & $338 / 1$ & $131 / 1$ & $338 / 1$ \\
$144 / 0$ & $380 / 4$ & $144 / 0$ & & $144 / 0$ & $416 / 0$ \\
$146 / 1$ & $413 / 3$ & $146 / 1$ & $146 / 1$ & $459 / 1 \& 2$ \\
$252 / 1$ & $416 / 0$ & $252 / 1$ & $252 / 1$ & $520 / 5$ \\
$337 / 0$ & $459 / 2$ & $337 / 0$ & $337 / 0$ & \\
$338 / 1$ & $520 / 5$ & $338 / 1$ & $338 / 1$ & \\
$370 / 0$ & & $370 / 0$ & $370 / 0$ &
\end{tabular}

Gondwanatheria

\begin{tabular}{|c|c|c|c|c|c|}
\hline 1013 & 1013cons & 1022 & 1022 cons & 1004 & 1004cons \\
\hline $359 / 1$ & $359 / 1$ & $359 / 1$ & / & $359 / 1$ & $359 / 1$ \\
\hline $362 / 1$ & $362 / 1$ & $362 / 1$ & & $362 / 1$ & $362 / 1$ \\
\hline $459 / 2$ & $368 / 1$ & $459 / 2$ & & & $368 / 1$ \\
\hline & $419 / 1$ & & & & $419 / 1$ \\
\hline & $421 / 1$ & & & & $421 / 1$ \\
\hline \multicolumn{6}{|c|}{ Multituberculata + Gondwanatheria } \\
\hline
\end{tabular}




\begin{tabular}{|c|c|c|c|c|c|}
\hline 1013 & 1013 cons & 1022 & 1022cons & 1004 & 1004cons \\
\hline $45 / 1$ & $59 / 1$ & $45 / 1$ & / & $45 / 1$ & $59 / 1$ \\
\hline $59 / 1$ & $82 / 1$ & $59 / 1$ & & $59 / 1$ & $82 / 1$ \\
\hline $68 / 1$ & $86 / 1$ & $68 / 1$ & & $68 / 1$ & $86 / 1$ \\
\hline $82 / 1$ & $128 / 1$ & $82 / 1$ & & $82 / 1$ & $128 / 1$ \\
\hline $86 / 1$ & $325 / 0$ & $86 / 1$ & & $86 / 1$ & $325 / 0$ \\
\hline $128 / 1$ & $332 / 1$ & $128 / 1$ & & $128 / 1$ & $332 / 1$ \\
\hline $325 / 0$ & $333 / 1$ & $325 / 0$ & & $325 / 0$ & $333 / 1$ \\
\hline $332 / 1$ & $379 / 1$ & $332 / 1$ & & $332 / 1$ & $379 / 1$ \\
\hline $333 / 1$ & & $333 / 1$ & & $333 / 1$ & $399 / 2$ \\
\hline $360 / 1$ & & $360 / 1$ & & $360 / 1$ & \\
\hline $379 / 1$ & & $379 / 1$ & & $379 / 1$ & \\
\hline $381 / 4$ & & $381 / 4$ & & $381 / 4$ & \\
\hline $384 / 2$ & & $384 / 2$ & & $384 / 2$ & \\
\hline $415 / 1$ & & $415 / 1$ & & $397 / 2$ & \\
\hline \multirow[t]{2}{*}{$468 / 1$} & & $468 / 1$ & & $415 / 1$ & \\
\hline & & & & $468 / 1$ & \\
\hline
\end{tabular}


TABLE 3. List of unambiguous synapomorphies for Adalatherium, Gondwanatheria, and Gondwanatheria + Taeniolabidoidea (undated only) and clade containing Gondwanatheria, Cifelliodon, Euharamiyida (tip-dated only), for undated and tip-dated Bayesian analyses.

\begin{tabular}{|c|c|c|c|c|c|}
\hline \multicolumn{6}{|c|}{ Adalatherium } \\
\hline 1013_undat & 1022_undat & 1004_undat & 1013_dated & 1022_dated & 1004_dated \\
\hline $122 / 0$ & $122 / 0$ & $337 / 0$ & $122 / 0$ & $122 / 0$ & $122 / 0$ \\
\hline $131 / 1$ & $131 / 1$ & $338 / 1$ & $131 / 1$ & $131 / 1$ & $131 / 1$ \\
\hline $144 / 0$ & $144 / 0$ & $416 / 0$ & $144 / 0$ & $144 / 0$ & $144 / 0$ \\
\hline $146 / 1$ & $146 / 1$ & $459 / 1 \& 2$ & $146 / 1$ & $146 / 1$ & $146 / 1$ \\
\hline $252 / 1$ & $252 / 1$ & $520 / 5$ & $252 / 1$ & $252 / 1$ & $252 / 1$ \\
\hline $337 / 0$ & $370 / 0$ & & $413 / 3$ & $337 / 0$ & $459 / 1 \& 2$ \\
\hline $338 / 1$ & $416 / 0$ & & $459 / 2$ & $338 / 1$ & $520 / 5$ \\
\hline \multirow[t]{4}{*}{$370 / 0$} & $417 / 0$ & & $520 / 5$ & $459 / 2$ & \\
\hline & $419 / 0$ & & & & \\
\hline & $421 / 0$ & & & & \\
\hline & $520 / 5$ & & & & \\
\hline
\end{tabular}

\section{Gondwanatheria}

\begin{tabular}{cccccc}
\hline 1013_undat & 1022_undat & 1004_undat & 1013_dated & 1022_dated & 1004_dated \\
$459 / 2$ & $419 / 1$ & $419 / 1$ & $/$ & $117 / 0$ & $/$ \\
& $421 / 1$ & $421 / 1$ & & $142 / 0$ & \\
& $463 / 1$ & $463 / 1$ & & $143 / 1$ &
\end{tabular}


$378 / 4$

Gondwanatheria + Taeniolabidoidea Gondwanatheria + Euharamiyida 1013_undat 1022_undat 1004_undat 1013_dated 1022_dated 1004_dated

$\begin{array}{llllll}38 / 1 & 38 / 1 & 38 / 1 & 51 / 1 & 51 / 1 & 51 / 1 \\ 129 / 2 & 129 / 2 & 129 / 2 & 60 / 1 & 60 / 1 & 60 / 1 \\ 150 / 0 & 150 / 0 & 150 / 0 & 206 / 0 & 206 / 0 & 106 / 1 \\ 165 / 2 & 165 / 2 & 165 / 2 & 292 / 0 & 292 / 0 & 200 / 0 \\ 227 / 0 & 227 / 0 & 227 / 0 & 459 / 0 & 459 / 0 & 206 / 0 \\ 307 / 1 & 307 / 1 & 307 / 1 & & & 225 / 1 \\ 346 / 1 & 346 / 1 & 346 / 1 & & & 284 / 1 \\ 380 / 4 & 381 / 4 & 381 / 4 & & & 292 / 0 \\ 381 / 4 & 387 / 0 & 387 / 0 & & & \\ 387 / 0 & 405 / 0 & 405 / 0 & & & \\ 405 / 0 & 412 / 0 & 412 / 0 & & & \\ 412 / 0 & & & & \end{array}$


A

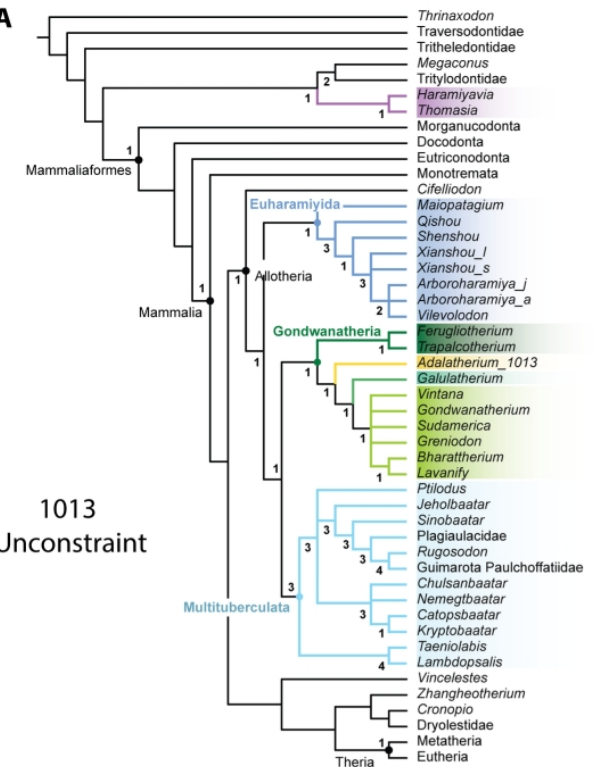

c

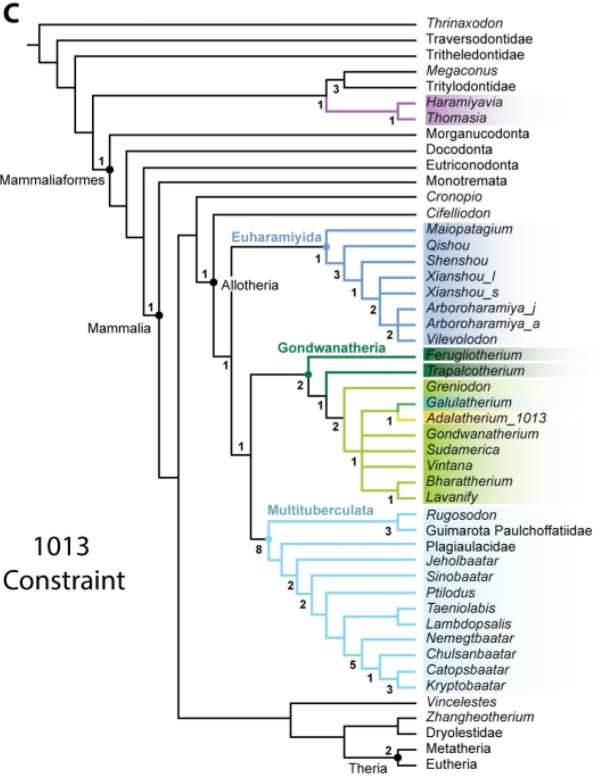

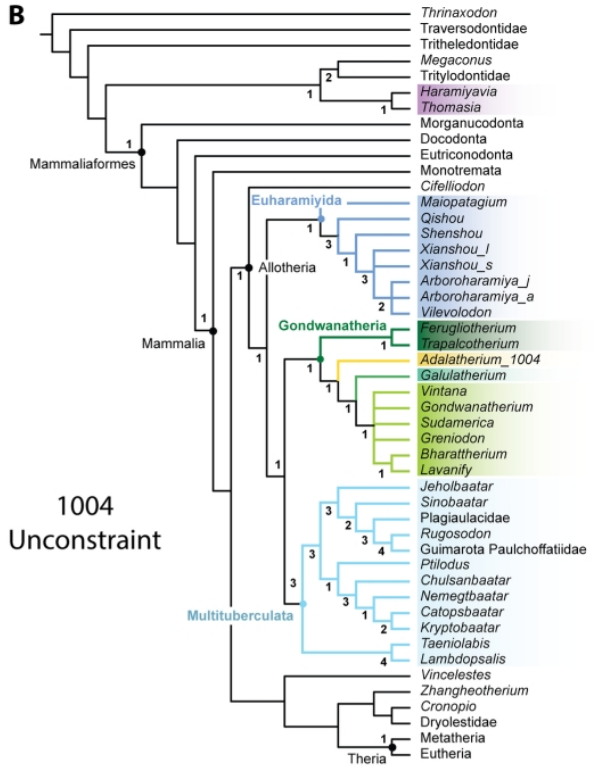

D

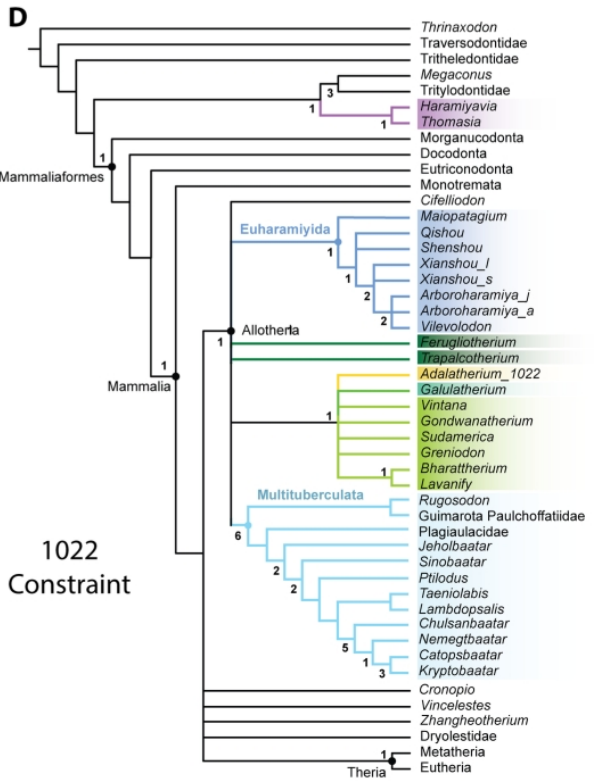

FIGURE 1. Simplified tree topology of strict consensus trees for parsimony analyses using three different coding schemes for Adalatherium based on lower dental formulae $(1013,1022,1004)$ with nodes within multituberculates either unconstrained (A, B) or constrained (C, D). A, simplified strict consensus tree of 16 most parsimonious trees (MPTs) from unconstrained analysis using coding scheme 1013 (tree topology but not Bremer support identical to 1022); B, simplified strict consensus tree of eight MPTs from unconstrained analysis using coding scheme 1004; C, simplified strict consensus tree of 16 MPTs from constrained analysis using coding scheme 1013 (tree topology but not Bremer support identical to 1004_constraint); D, simplified strict consensus tree of 40 MPTs from constrained analysis using coding scheme 1022. Bremer values for selected nodes indicated next to node. Adalatherium highlighted in yellow, gondwanatherians in green shades (ferugliotheriids in dark green, Galulatherium in teal, sudamericids in light green), multituberculates in light blue, euharamiyidans in dark blue, haramiyidans in purple. [planned for page width, color] 
2

3

4

$181 \times 232 \mathrm{~mm}(300 \times 300$ DPI $)$

6

7

8

9

10

11

12

13

14

15

16

17

18

19

20

21

22

23

24

25

26

27

28

29

30

31

32

33

34

35

36

37

38

39

40

41

42

43

44

45

46

47

48

49

50

51

52

53

54

55

56

57

58

59

60

Society of Vertebrate Paleontology 

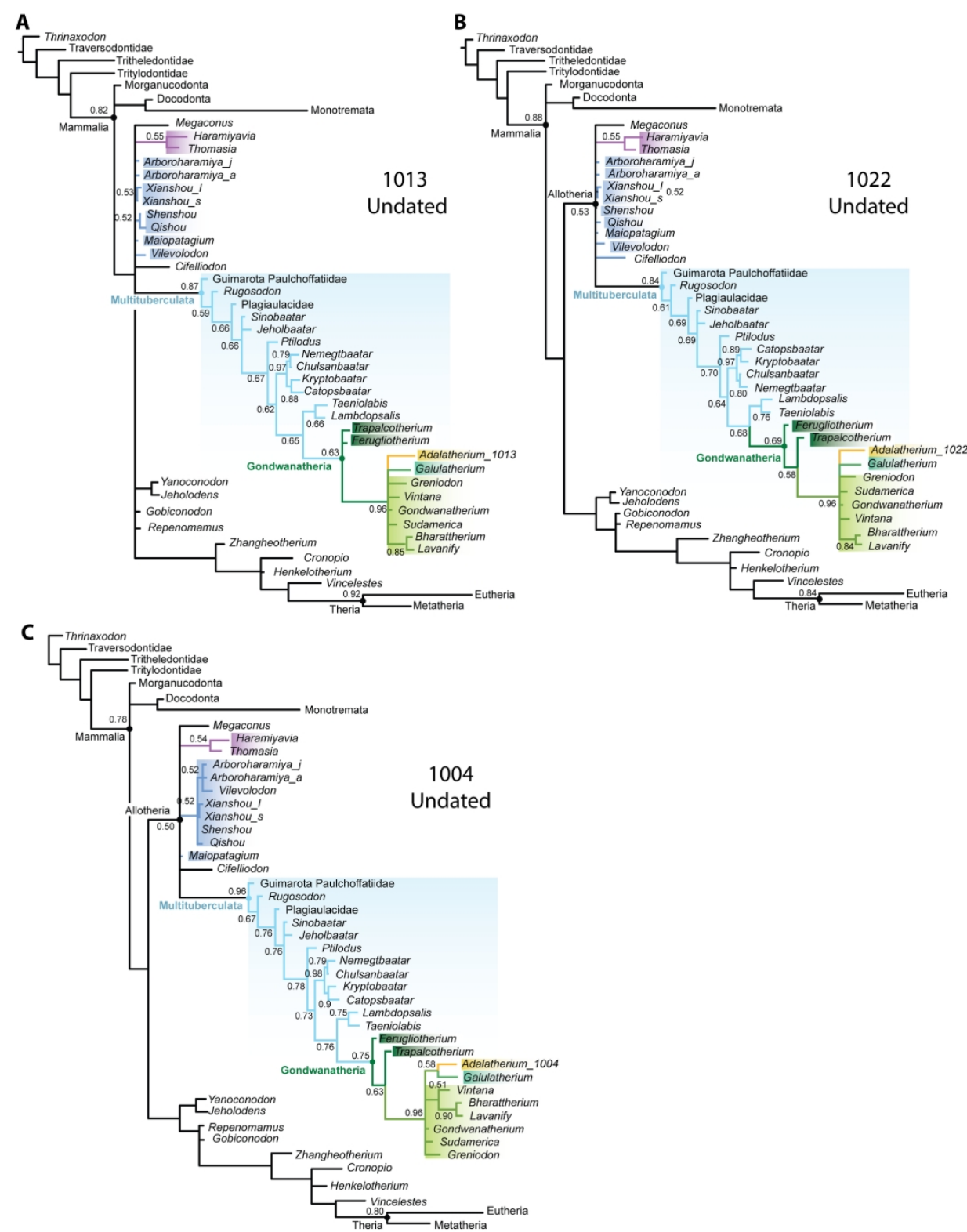

FIGURE 2. Simplified tree topology of 'halfcompat' (50\% majority rule) trees for undated Bayesian analyses using three different coding schemes for Adalatherium based on lower dental formulae $(1013,1022,1004)$. A, simplified halfcompat tree of 1013_undated; B, simplified halfcompat tree of 1022_undated; and C, simplified halfcompat tree of 1004_undated. Posterior probabilities for selected nodes indicated next to node. Adalatherium highlighted in yellow, gondwanatherians in green shades (ferugliotheriids - dark, Galulatherium - medium, sudamericids - light), multituberculates in light blue, euharamiyidans in dark blue, haramiyidans in purple. [planned for page width, color]

$$
182 \times 232 \mathrm{~mm}(300 \times 300 \mathrm{DPI})
$$



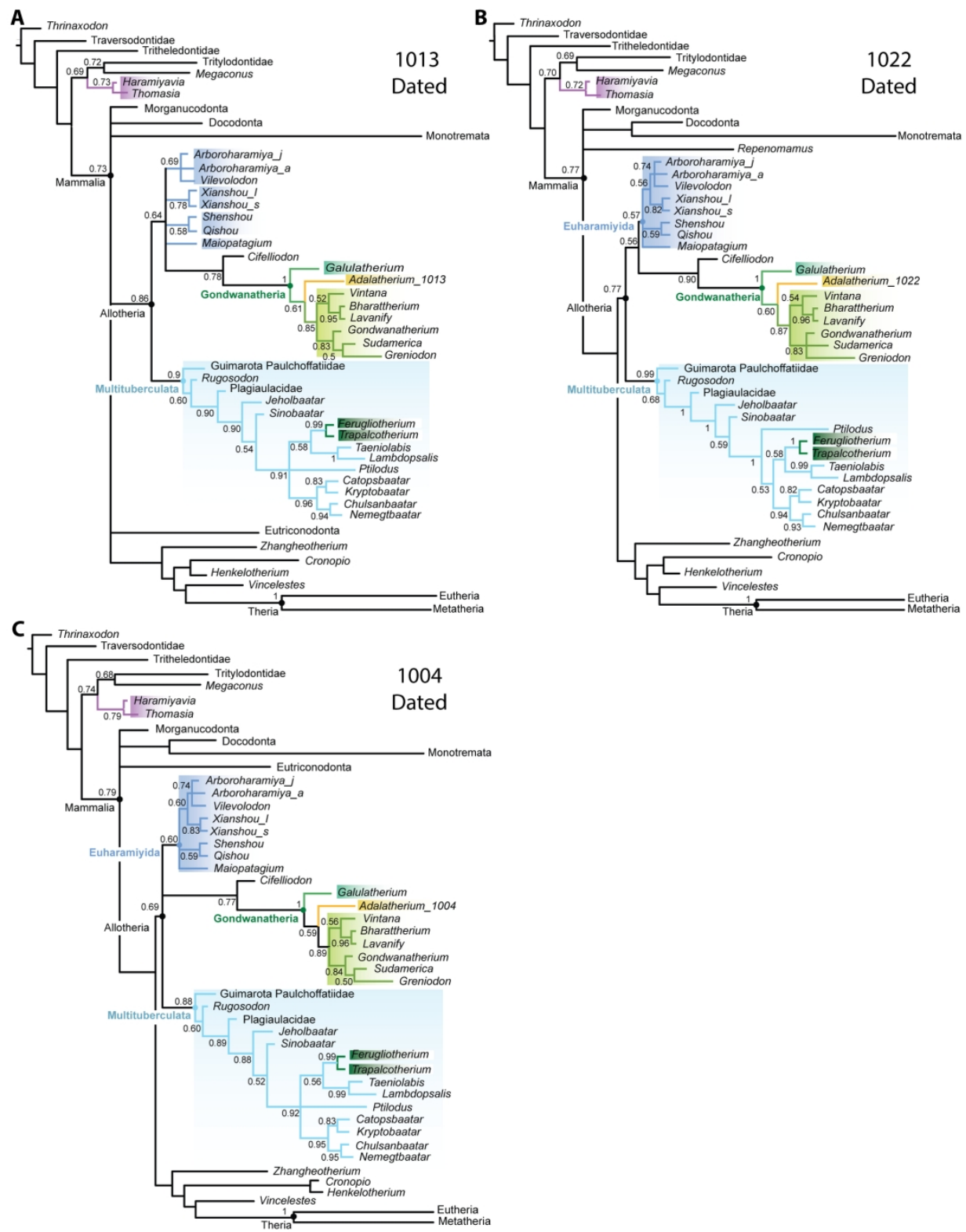

FIGURE 3. Simplified tree topology of 'halfcompat' ( $50 \%$ majority rule) trees for tip-dated Bayesian analyses using three different coding schemes for Adalatherium based on lower dental formulae $(1013,1022,1004)$. A, simplified halfcompat tree of 1013_dated; B, simplified halfcompat tree of 1022_dated; and C, simplified halfcompat tree of 1004_dated. Posterior probabilities for selected nodes indicated next to node.

Adalatherium highlighted in yellow, gondwanatherians in green shades (ferugliotheriids in dark green, Galulatherium in teal, sudamericids in light green), multituberculates in light blue, euharamiyidans in dark blue, haramiyidans in purple. [planned for page width, color]

\section{$182 \times 232 \mathrm{~mm}(300 \times 300$ DPI $)$}


A Zhou et al. (2013)

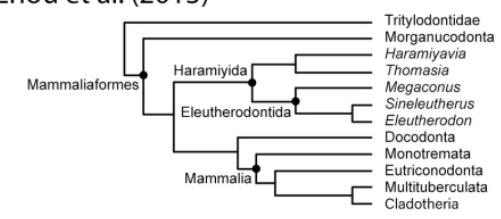

C Krause et al. (2014)

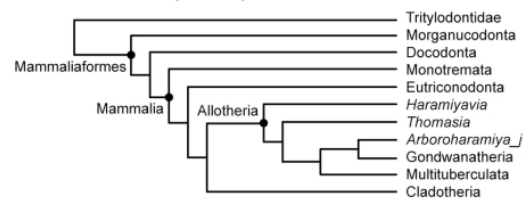

E Luo et al. (2015)

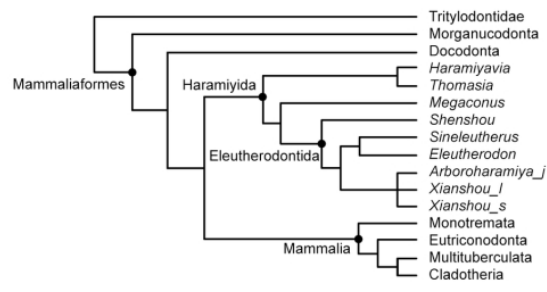

G Huttenlocker et al. (2018)

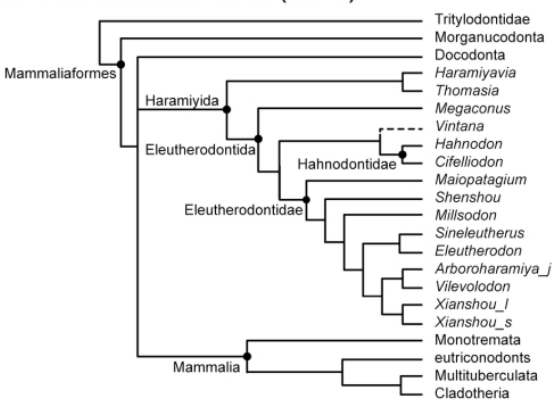

B Zheng et al. (2013)

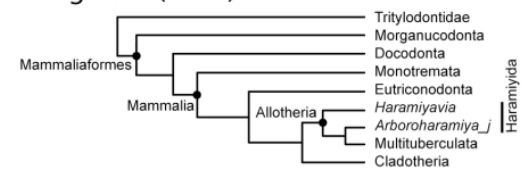

D Bi et al. (2014)

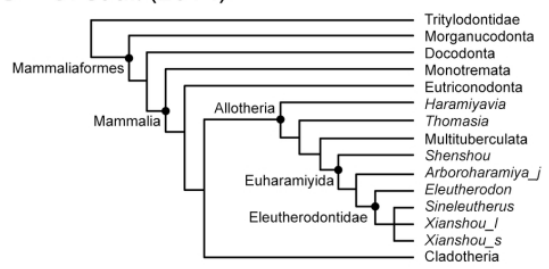

F Luo et al. (2017)

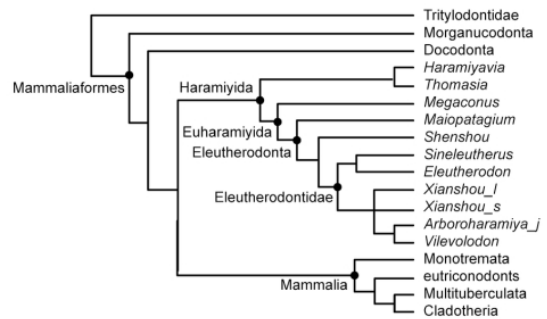

H Han et al. (2017)

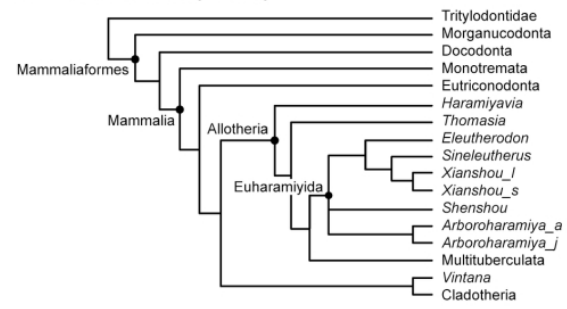

FIGURE 4. Simplified tree topology of mammaliaform relationships based on A, Zhou et al. (2013); B, Zheng et al. (2013); C, Krause et al. (2014); D, Bi et al. (2014); E, Luo et al. (2015); F, Luo et al. (2017); G, Huttenlocker et al. (2018); and $\mathrm{H}$, Han et al. (2017). Millsodon, Allostaffia, Theroteinida were not included in the analysis of $\mathrm{Bi}$ et al. (2014:Supplementary Information), but the authors assigned Millsodon to Euharamiyida, and Allostaffia and Theroteinida to Allotheria. Megaconus was included in one of three analyses by $\mathrm{Bi}$ et al. (2014:Supplementary Information) and was assigned to Allotheria, contrary to its placement in their analyses. These taxa are not included in part D. Eutriconodonta are not monophyletic in $\mathrm{F}$ and $\mathrm{G}$ and are therefore labeled as 'eutriconodonts.' [planned for page width, grayscale]

$182 \times 196 \mathrm{~mm}(300 \times 300 \mathrm{DPI})$ 